Supporting Information: Reactivity and DNA Damage by Independently Generated 2'-Deoxycytidin- $N 4$ yl Radical

Haihui Peng ${ }^{\mathrm{a} *}$, Jialong Jie ${ }^{\mathrm{b} *}$, Ifor P. Mortimer ${ }^{\mathrm{a}}$, Zehan $\mathrm{Ma}^{\mathrm{b}}$, Hongmei $\mathrm{Su}^{* \mathrm{~b}}$ and Marc M. Greenberg ${ }^{* \mathrm{a}}$

${ }^{a}$ Department of Chemistry, Johns Hopkins University, MD 21218, United States

${ }^{b}$ Department of Chemistry, Beijing Normal University, Beijing 100875, P. R. China

Author Contributions \# These authors contributed equally.

mgreenberg@jhu.edu, hongmei@bnu.edu.cn

\title{
Contents:
}

Experimental procedures. (S3-S9)

Figure S1. $E / Z$ isomer of $6 \mathbf{a}$ and $6 \mathbf{b}$ in $d_{6}$-DMSO. (S10)

Figure S2. UV-VIS absorbance spectra of $6 \mathbf{a}$ and $\mathbf{6 b}$. (S10)

Table S1. Retention times and response factors for HPLC analysis. (S10)

Table S2. Photolysis of $\mathbf{6 a} / \mathbf{6 b}$ in anaerobic and aerobic conditions. (S11)

Figure S3. Total ion chromatogram (TIC) of the photolysate of $\mathbf{6 a}$ under aerobic conditions. (S11)

Scheme S1. Proposed mechanism for 7/8/8-OH formation after aerobic photolysis of $\mathbf{6 a}$. (S12)

Figure S4. Mass spectrum of chromatographic analysis of the aerobic photolysate of 6a. (S13)

Figure S5. HPLC analysis of BME and $\mathrm{O}_{2}$ effect on the photolysis of $\mathbf{6 a} / \mathbf{6 b}$. (S14-S16)

Figure S6. Time-resolved UV-VIS absorption spectra for ArO• radical. (S17)

Figure S7. Monitoring dC • generation and its reactivity towards $\mathrm{O}_{2}$. $(\mathrm{S} 17)$

Figure S8. Kinetics traces of the $400 \mathrm{~nm}$ band after $355 \mathrm{~nm}$ laser photoexcitation of $6 \mathbf{a}$ or $\mathbf{6 b}$. (S18)

Figure S9. Effect of laser pulse energy on photolysis of 6a. (S18)

Figure S10. Transient absorption spectra of $\mathrm{dG} \bullet+/ \mathrm{dG}(-\mathrm{H}) \bullet$ obtained at $\mathrm{t}=500 \mathrm{~ns}$ after $355 \mathrm{~nm}$ laser flash photolysis of $\mathrm{Na}_{2} \mathrm{~S}_{2} \mathrm{O}_{8}$. (S18)

Figure S11. Kinetics traces of laser photoexcitation of $6 \mathbf{a}, \mathbf{6 a}+\mathrm{dG}, \mathbf{6 a}+\mathrm{dA}, \mathbf{6 a}+\mathrm{dC}$, and $\mathbf{6 a}+\mathrm{T}$. (S18)

Scheme S2. Conversion of $\mathrm{ArO} \bullet$ into $\mathrm{HO}-\mathrm{ArO} \bullet$. (S18)

Figure S12. Photolysis of $5{ }^{\prime}{ }^{32} \mathrm{P}-15$. (S19)

Figure S13. Photolysis of $5{ }^{3}-{ }^{32} \mathrm{P}-\mathbf{1 5}$, followed by $\mathrm{NaBH}_{4} / \mathrm{Pip}$ treatments. (S20)

Figure S14. Photolysis of $5{ }^{\prime}{ }^{32} \mathrm{P}-18$. (S21)

Figure S15. Photolysis of $3^{\prime}{ }^{32} \mathrm{P}-17$. (S22)

Figure S16. Photolysis of $5{ }^{3}{ }^{32} \mathrm{P}-16$. (S23)

Figure S17. Mass spectral characterization of 19. (S24)

Figure S18. Mass spectral characterization of 20. (S25)

Figure S19. Mass spectral characterization of 21. (S26)

Figure S20. Photolysis of 5, ${ }^{32} \mathrm{P}-22$ labeled on the modified strand. (S27)

Figure S21. Photolysis of $5^{,}-{ }^{32} \mathrm{P}-22$ labeled on the opposite strand. (S28)

Figure S22. Photolysis of $5{ }^{3}-{ }^{32} \mathrm{P}-15$ labeled on the opposite strand. (S29)

Figure S23. Photolysis of $5{ }^{3}-{ }^{32} \mathrm{P}-23$ labeled on the opposite strand. (S30)

Figure S24. Photolysis of $5^{\prime}{ }^{32} \mathrm{P}-24$ labeled on the GGG containing strand. (S31)

Figure S25. Photolysis of 5 ${ }^{3}{ }^{32} \mathrm{P}-27$ labeled on the opposite strand. (S32)

Figure S26. Photolysis of 5 ${ }^{3}{ }^{32} \mathrm{P}-27$ labeled on the modified strand. (S33)

Figure S27. LC-MS and ESI-MS analysis of oligonucleotides containing 6a or O6-Me-dG. (S33-S38)

Figure S28. ${ }^{1} \mathrm{H}$ NMR of 4 . (S38)

Figure S29. ${ }^{1} \mathrm{H}$ NMR and ${ }^{31} \mathrm{C}$ NMR, of 5a. (S39)

Figure S30. ${ }^{1} \mathrm{H}$ NMR and ${ }^{31} \mathrm{C}$ NMR, of 6a. (S40)

Figure S31. ${ }^{1} \mathrm{H}$ NMR and ${ }^{31} \mathrm{C}$ NMR, of 5b. (S41)

Figure S32. ${ }^{1} \mathrm{H}$ NMR and ${ }^{31} \mathrm{C}$ NMR, of $\mathbf{6 b}$. (S42) 
Figure S33. ${ }^{1} \mathrm{H}$ NMR and ${ }^{31} \mathrm{C}$ NMR of 29a. (S43)

Figure S34. ${ }^{1} \mathrm{H}$ NMR, ${ }^{31} \mathrm{C}$ NMR, and ${ }^{31} \mathrm{P}$ NMR of 30a. (S44-45)

Figure S35. Orbital contour plot of the HOMO for dG and MeG. (S45)

References (S46) 
General methods. THF was distilled over Na/benzophenone. DCM, TEA, DIPEA and pyridine were distilled over $\mathrm{CaH}_{2}$. The other reagents were obtained from commercial sources and were directly used without further purification unless noted otherwise. All reactions were performed under a positive pressure of argon atmosphere and monitored by TLC. 2'-Deoxyguanosine (dG), 2'-Deoxyadenosine (dA), 2'Deoxycytidine (dC), Thymidine (T), p-nitrophenol $\left(p\right.$-NP), and acetonitrile $\left(\mathrm{CH}_{3} \mathrm{CN}\right)$ were purchased from Sigma Aldrich. T4 polynucleotide kinase was obtained from New England Biolabs and $\gamma^{3}{ }^{32} \mathrm{P}$-ATP was purchased from Perkin Elmer. C18-Sep-Pak cartridges were obtained from Waters and Poly-Prep columns from Bio-Rad. Nuclear magnetic resonance spectra were acquired on Bruker $400 \mathrm{MHz}$ for ${ }^{1} \mathrm{H}, 101 \mathrm{MHz}$ for ${ }^{13} \mathrm{C}$ and $162 \mathrm{MHz}$ for ${ }^{31} \mathrm{P}$. High resolution ESI mass spectra for HRMS of synthesized molecules were recorded on a Waters Acquity/Xevo-G2UPLC-MS system in positive mode.

Nucleoside experiments. Photolyses were carried out in Pyrex tubes using a Rayonet photochemical reactor (Southern New England Ultraviolet) equipped with a merry-go-round apparatus and 16 lamps having a maximum output at $350 \mathrm{~nm}$ at $25^{\circ} \mathrm{C}$. This temperature was maintained by using the fan at the bottom of the unit provided by the manufacturer and a Dayton ${ }^{\circledR} 239$ CFM AC axial fan at the top facing such that air flowing through the unit is drawn out through the top. Reaction mixtures (50 $\mu \mathrm{L}$ each) containing precursor $(100 \mu \mathrm{M})$, internal standard (thymidine, $100 \mu \mathrm{M})$, and additives (e.g. reducing agents, organic solvent) in buffer (10 mM phosphate, $100 \mathrm{mM} \mathrm{NaCl}, \mathrm{pH} 7.2)$ were photolyzed at room temperature under aerobic or anaerobic conditions. Samples for anaerobic reactions were degassed by three freeze-pump-thaw cycles at 2 mTorr and flame sealed under vacuum. Yields (\%) are shown as average \pm std. dev. of 3 replicates.

The reaction mixtures (including unphotolyzed controls) were analyzed by reversed-phase HPLC while being monitored at $260 \mathrm{~nm}$ and $284 \mathrm{~nm}$. HPLC was performed on a Phenomenex Luna C-18 column (A, 10 $\mathrm{mM}$ ammonium formate; $\mathrm{B}, \mathrm{ACN} ; 3 \% \mathrm{~B}$ from $\mathrm{t}=0$ to $\mathrm{t}=1 \mathrm{~min} ; 3-28 \% \mathrm{~B}$ linearly over $9 \mathrm{~min} ; 28-97 \% \mathrm{~B}$ linearly over $5 \mathrm{~min}$; $97 \% \mathrm{~B}$ from $\mathrm{t}=25$ to $\mathrm{t}=20 \mathrm{~min}$; $97-3 \% \mathrm{~B}$ linearly over $2 \mathrm{~min} ; 3 \% \mathrm{~B}$ from $\mathrm{t}=22 \mathrm{to} \mathrm{t}=$ $40 \mathrm{~min}$; flow rate, $1 \mathrm{~mL} / \mathrm{min}$ ). Response factor (Rf) for compound $\mathrm{X}$ versus thymidine was calculated using the following formula: $([\mathrm{X}] /[\mathrm{dT}])=\operatorname{Rf}(\mathrm{A}(\mathrm{X}) / \mathrm{A}(\mathrm{dT}))$, where $[\mathrm{X}]$ is the concentration of compound $\mathrm{X}$ and $[\mathrm{dT}]$ is the concentration of $\mathrm{dT} . \mathrm{A}(\mathrm{X})$ and $\mathrm{A}(\mathrm{dT})$ are the areas under the peaks corresponding to $\mathrm{X}$ versus $\mathrm{dT}$. The retention times of the internal standard, precursors, and products generated by photolysis are listed in Table S1. The peaks were integrated and quantified against the internal standard (thymidine), and the response factors are reported in Table $\mathbf{S 1}$.

Oligonucleotide synthesis and purification. Oligonucleotides were synthesized on an Applied Biosystems Incorporated 394 oligonucleotide synthesizer or purchased from IDT. Oligonucleotide synthesis reagents were purchased from Glen Research (Sterling, VA). ESI-MS of oligonucleotides was carried out on a ThermoFisher Scientific LCQ Fleet ion trap instrument.

Commercially available CE phosphoramidites were used for synthesizing unmodified oligonucleotides. Deprotection of unmodified oligonucleotides was performed with concentrated aqueous ammoniamethylamine $(\mathrm{v} / \mathrm{v}=1: 1,1 \mathrm{~mL})$ at $65^{\circ} \mathrm{C}$ for $1 \mathrm{~h}$, followed by concentration under reduced pressure.

Commercially available UltraMild CE phosphoramidites and UltraMild Cap Mix A (5\% phenoxyacetic 
anhydride in THF/pyridine) were used for DNA synthesis of oligonucleotides containing $\mathbf{6 a}$ and $\mathrm{O}^{6}$-Me-dG. A 5 min coupling time was used for the 6a and $\mathrm{O}^{6}-\mathrm{Me}-\mathrm{dG}$ phosphoramidite. Deprotection of synthesized oligonucleotides containing $\mathbf{6 a}$ was performed with concentrated aqueous ammonia at room temperature for $12 \mathrm{~h}$, followed by concentration under reduced pressure. Deprotection of synthesized oligonucleotides containing $\mathrm{O}^{6}-\mathrm{Me}-\mathrm{dG}$ was performed with concentrated aqueous ammonia at $50{ }^{\circ} \mathrm{C}$ for $12 \mathrm{~h}$, followed by concentration under reduced pressure.

The oligonucleotides were purified using 20\% denaturing PAGE. Oligonucleotides were exercised from polyacrylamide gel, crushed and eluted with elution buffer (10 mL, $200 \mathrm{mM} \mathrm{NaCl}, 1 \mathrm{mM}$ EDTA) at room temperature for $12 \mathrm{~h}$ and desalted using C18-Sep-Pak cartridges. The extinction coefficients at $260 \mathrm{~nm}$ of modified oligonucleotide were calculated using IDT OligoAnalyzer® program based on nearest neighbor method, and the modified nucleotide were treated as their unmodified counterparts. The concentrations of oligonucleotides were determined using their absorbance at $260 \mathrm{~nm}$.

UV melting experiments. Solutions containing a single-stranded oligonucleotide $(2.4 \mu \mathrm{M})$ and their corresponding complementary oligonucleotide $(2.4 \mu \mathrm{M})$ were prepared in hybridization buffer $(200 \mu \mathrm{L}, 100$ $\mathrm{mM} \mathrm{NaCl}, 10 \mathrm{mM}$ sodium phosphate, $\mathrm{pH}$ 7.2) and were hybridized by heating the samples to $75^{\circ} \mathrm{C}$ and slowly cooled to $17^{\circ} \mathrm{C}$. Melting studies were carried out in $1 \mathrm{~cm}$ path length quartz cells. Absorbance at 260 $\mathrm{nm}$ was monitored while the temperature was ramped at a rate of $0.5^{\circ} \mathrm{C} / \mathrm{min}$ from $20^{\circ} \mathrm{C}$ to $75^{\circ} \mathrm{C}$.

Radiolabeling and DNA photolysis. The strand $(1 \mu \mathrm{M})$ containing the radical precursor was labeled at the 5'-terminus with $\gamma_{-}{ }^{32} \mathrm{P}$-ATP using T4 PNK (30 units) in T4 PNK buffer (70 mM Tris-HCl, pH 7.6, $10 \mathrm{mM}$ $\mathrm{MgCl}_{2}, 5 \mathrm{mM}$ DTT, $2 \mathrm{~h}, 37^{\circ} \mathrm{C}$ ). The labeled strand was hybridized to the complementary strand (1.5 eq.) in PBS by heating at $70^{\circ} \mathrm{C}$ for $5 \mathrm{~min}$ and slowly cooling to room temperature. The hybridized duplexes were diluted to $10 \mathrm{nM}$ in PBS buffer (100 mM NaCl, $10 \mathrm{mM}$ sodium phosphate, $\mathrm{pH}$ 7.2) before photolysis. All photolyses were carried out in Pyrex tubes for $30 \mathrm{~min}$. Quantification of radiolabeled oligonucleotides was carried out using a Molecular Dynamics Phosphorimager 860 equipped with ImageQuant Version TL software.

Post-photolysis oligonucleotide treatments. Aliquots from photolyzed solutions or unphotolyzed controls were treated with piperidine $\left(1 \mathrm{M}, 30 \mathrm{~min}, 90^{\circ} \mathrm{C}\right), \mathrm{Fpg}(1.25 \mu \mathrm{M}, 1 \mu \mathrm{L}, 10 \mathrm{mM}$ Bis Tris-Propane $\mathrm{HCl}(\mathrm{pH}$ 7), $10 \mathrm{mM} \mathrm{MgCl} 2,1 \mathrm{mM}$ DTT, $100 \mu \mathrm{g} / \mathrm{mL} \mathrm{BSA}, 1 \mathrm{~h}, 37^{\circ} \mathrm{C}$ ). Alternatively, photolysates were treated with piperidine $\left(1 \mathrm{M}, 30 \mathrm{~min}, 90^{\circ} \mathrm{C}\right)$ in the presence of $\mathrm{BME}(0.7 \mathrm{M})$. In addition, the photolysates were treated with $\mathrm{NaBH}_{4}\left(100 \mathrm{mM}, 1 \mathrm{~h}, 4{ }^{\circ} \mathrm{C}\right)$, prior to piperidine treatment $\left(1 \mathrm{M}, 30 \mathrm{~min}, 90^{\circ} \mathrm{C}\right)$. All samples treated with enzymes were precipitated (0.3 M NaOAc, $\mathrm{pH} 5.2,0.1 \mathrm{~g} / \mathrm{mL}$ calf thymus DNA) with ethanol. Piperidine treated samples were evaporated to dryness under vacuum and washed with $2 \times 10 \mu \mathrm{L}$ water, which was also removed under vacuum. Samples were analyzed by dissolving in formamide loading buffer prior to analyzing by $20 \%$ denaturing PAGE. BME $(0.7 \mathrm{M})$, piperidine $(1 \mathrm{M})$, and $\mathrm{NaBH}_{4}(100 \mathrm{mM})$ solutions were prepared fresh on the day of the experiment.

The amount of cleavable DNA damage was background subtracted. For the relation $y=a-b$, the standard deviation of $\mathrm{y}$ is: 


$$
\delta_{\mathrm{y}}=\sqrt{\delta_{\mathrm{a}}^{2}+\delta_{\mathrm{b}}^{2}}
$$

where $a$ is the cleavage amount of damaged DNA from photolysates, $b$ is the cleavage amount from unphotolyzed controls, and y is the background subtracted cleavage amount from photolysates. $\delta_{\mathrm{a}}, \delta_{\mathrm{b}}$, and $\delta_{\mathrm{y}}$ are the respective variances.

UPLC-MS/MS Analysis of Oligonucleotides after photolysis. Photolysates $(10 \mu \mathrm{L})$ containing $10 \mu \mathrm{M}$ of duplex dodecamer were analyzed by UPLC-MS/MS using the Oligonucleotide BEH C18 Column (A, 100 $\mathrm{mM}$ HFIP and $8.6 \mathrm{mM}$ TEA; $\mathrm{B}$, Methanol; $2 \%$ to $5 \% \mathrm{~B}$ from $\mathrm{t}=0$ to $\mathrm{t}=3 \mathrm{~min} ; 5 \%$ to $10 \% \mathrm{~B}$ from $\mathrm{t}=3$ to $\mathrm{t}=10 \mathrm{~min} ; 10 \%$ to $15 \% \mathrm{~B}$ from $\mathrm{t}=10$ to $\mathrm{t}=20 \mathrm{~min} ; 15 \%$ to $30 \% \mathrm{~B}$ from $\mathrm{t}=20$ to $\mathrm{t}=25 \mathrm{~min} ; 30 \% \mathrm{~B}$ from $\mathrm{t}=25$ to $\mathrm{t}=30 \mathrm{~min} ; 30 \%$ to $2 \% \mathrm{~B}$ from $\mathrm{t}=30$ to $\mathrm{t}=35 \mathrm{~min} ; 2 \% \mathrm{~B}$ from $\mathrm{t}=35$ to $\mathrm{t}=40 \mathrm{~min}$; flow rate, 0.2 $\mathrm{mL} / \mathrm{min}$ ). The column temperature was $60^{\circ} \mathrm{C}$. The collision energy was set to ramp from 10 to $45 \mathrm{~V}$.

Laser Flash Photolysis. Nanosecond time-resolved transient absorption spectra were measured using a flash photolysis setup Edinburgh LP980 spectrometer (Edinburgh Instruments Ltd.) combined with a Nd:YAG laser (Spectra-Physics Lab 170, Newport Corp.). Each measurement was performed in a quartz cuvette with $1 \mathrm{~cm}$ path length at room temperature. To keep the sample fresh, the solution was constantly circulated during laser experiments. The sample was excited by a $355 \mathrm{~nm}$ laser pulse $\left(1 \mathrm{~Hz}, 25 \mathrm{~mJ} / \mathrm{pulse} / \mathrm{cm}^{2}\right.$, fwhm $\approx 7 \mathrm{~ns}$ ). The analyzing light was from a $150 \mathrm{~W}$ pulsed xenon lamp. A monochromator equipped with a photomultiplier for collecting the spectral range from 300 to $700 \mathrm{~nm}$ was used to analyze transient absorption spectra. The signals from the photomultiplier were displayed and recorded as a function of time on a $100 \mathrm{MHz}(1.25 \mathrm{Gs} / \mathrm{s}$ sampling rate) oscilloscope (Tektronix, TDS 3012C), and the data were transferred to a personal computer. Data were analyzed by the online software of the LP980 spectrophotometer. The fitting quality was judged by weighted residuals and reduced $\chi^{2}$ value.

Computational Methods. The geometries were fully optimized at the B3LYP/6-31++G(d,p) level of theory. The HOMO orbital and HOMO energy were obtained at the same level. Bulk solvation effects were simulated by using the polarizable continuum model (PCM). The calculations were carried out using the Gaussian 09 program package. ${ }^{1}$ Gauss View molecular modeling software was used to plot the molecular orbitals and draw the molecular structure. 


\section{Preparation of $\mathrm{dC}$ radical precursors.}

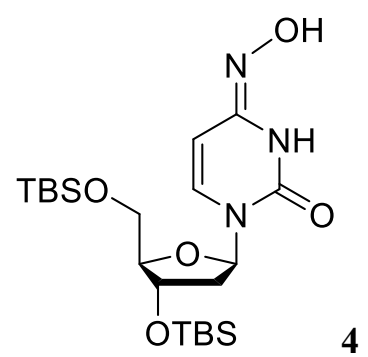

To a mixture of 1,2,4-triazole $(3.11 \mathrm{~g}, 45 \mathrm{mmol})$ in $\mathrm{MeCN}(20 \mathrm{~mL})$ at $0{ }^{\circ} \mathrm{C}$, phosphoryl chloride $(1.53 \mathrm{~g}, 10$ mmol) was added over $2 \mathrm{~min}$. The mixture was stirred at $0{ }^{\circ} \mathrm{C}$ for $10 \mathrm{~min}$. Triethylamine $(4.55 \mathrm{~g}, 45 \mathrm{mmol})$ was added over $5 \mathrm{~min}$, and the solution was stirred at $0{ }^{\circ} \mathrm{C}$ for another $20 \mathrm{~min}$. 3', 5'-O-Di(tertbutyldimethylsilyl)-2'-deoxyuridine $(2.28 \mathrm{~g}, 5 \mathrm{mmol})$ was added. The mixture was stirred at room temperature overnight. The reaction was quenched with $4.0 \mathrm{~mL}$ of $\mathrm{Et}_{3} \mathrm{~N}$ and $1.1 \mathrm{~mL}$ of water. The solvent was removed under reduced pressure. The residue was partitioned between EtOAc $(100 \mathrm{~mL})$ and saturated aqueous $\mathrm{NaHCO}_{3}(50 \mathrm{~mL})$. The organic layer was concentrated under reduced pressure. The residue was dissolved in pyridine $(10 \mathrm{~mL})$. Hydroxylamine hydrochloride $(0.56 \mathrm{~g}, 8 \mathrm{mmol})$ were added. The mixture was stirred overnight. The solvent was evaporated to dryness under vacuum. The crude product was purified by column chromatography (Hex/EtOAc, 9:1 to 3:1) to yield 4 as a colorless solid (1.95 g, $4.2 \mathrm{mmol}, 83 \%$ ). ${ }^{2}$ ${ }^{1} \mathrm{H}$ NMR (400 MHz, CDCl $) \delta 7.29(\mathrm{~s}, 1 \mathrm{H}), 7.18(\mathrm{dd}, J=1.2,8.0 \mathrm{~Hz}, 1 \mathrm{H}), 6.33(\mathrm{t}, J=6.4 \mathrm{~Hz}, 1 \mathrm{H}), 5.61(\mathrm{~d}$, $J=8.4 \mathrm{~Hz}, 1 \mathrm{H}), 4.42(\mathrm{ddd}, J=5.8,3.0 \mathrm{~Hz}, 1 \mathrm{H}), 3.69(\mathrm{ddd}, J=3.2,6.4 \mathrm{~Hz}, 1 \mathrm{H}), 3.91-3.88(\mathrm{~m}, 2 \mathrm{H}), 3.76$ $(\mathrm{dd}, \mathrm{J}=2.0,11.2 \mathrm{~Hz}, 1 \mathrm{H}), 2.23-2.18(\mathrm{~m}, 1 \mathrm{H}), 2.08-2.02(\mathrm{~m}, 1 \mathrm{H}), 0.95(\mathrm{~s}, 9 \mathrm{H}), 0.90(\mathrm{~s}, 9 \mathrm{H}), 0.12(\mathrm{~s}, 3 \mathrm{H})$, $0.11(\mathrm{~s}, 3 \mathrm{H}), 0.10$ (s, 3H), 0.09 (s, 3H).<smiles>CC(C)(C)OCC1OC2OCCCC12n1ccc(=NOc2ccc([N+](=O)[O-])cc2)[nH]c1=O</smiles>

Compound 4 (471 mg, $1.0 \mathrm{mmol}$ ) was added to THF ( $2 \mathrm{~mL})$. The reaction mixture was cooled to $0{ }^{\circ} \mathrm{C}$ and $\mathrm{NaH}(40 \%$ dispersion in mineral oil, $90.0 \mathrm{mg}, 1.5 \mathrm{mmol})$ was slowly added under Ar. The mixture was allowed to warm to room temperature over $1 \mathrm{~h}$, then $p$-nitro-fluorobenzene $(211 \mathrm{mg}, 1.5 \mathrm{mmol})$ was added and the mixture was warmed to $60{ }^{\circ} \mathrm{C}$ and stirred overnight. The mixture was cooled to room temperature and diluted with $\mathrm{H}_{2} \mathrm{O}$ and EtOAc. The layers were separated and the aqueous layer was extracted with EtOAc $(15 \mathrm{~mL} \times 2)$. The combined organic layers were dried $\left(\mathrm{MgSO}_{4}\right)$, filtered and evaporated to dryness under vacuum. The crude product was purified by column chromatography (Hex/EtOAc, 9:1 to 3:1) to yield 5a as a light yellow solid (432 mg, 73\%). ${ }^{1} \mathrm{H}$ NMR (400 MHz, $\left.\mathrm{CDCl}_{3}\right) \delta 8.93(\mathrm{~s}, 1 \mathrm{H}), 8.22(\mathrm{~d}, J=9.2 \mathrm{~Hz}, 2 \mathrm{H})$, $7.44(\mathrm{~d}, J=8.4 \mathrm{~Hz}, 1 \mathrm{H}), 7.32(\mathrm{~d}, J=9.2 \mathrm{~Hz}, 2 \mathrm{H}), 6.36(\mathrm{t}, J=6.8 \mathrm{~Hz}, 1 \mathrm{H}), 5.72(\mathrm{~d}, J=8.0 \mathrm{~Hz}, 1 \mathrm{H}), 4.46$ $4.43(\mathrm{~m}, 1 \mathrm{H}), 3.94$ (d, $J=2.4 \mathrm{~Hz}, 1 \mathrm{H}), 3.90$ (dd, $J=2.4,12.0 \mathrm{~Hz}, 1 \mathrm{H}), 3.78$ (dd, $J=2.0,11.2 \mathrm{~Hz}, 1 \mathrm{H}), 2.24$ - $2.21(\mathrm{~m}, 1 \mathrm{H}), 2.12$ - $2.01(\mathrm{~m}, 1 \mathrm{H}), 0.95$ (s, 9H), 0.89 (s, 9H), 0.13 (s, 6H), 0.09 (s, 6H). ${ }^{13} \mathrm{C}$ NMR (101 
$\left.\mathrm{MHz}, \mathrm{CDCl}_{3}\right) \delta 163.5,149.0,148.1,142.1,133.0,125.7,114.1,97.0,87.7,84.5,71.8,62.8,41.2,25.9,25.7$, $18.4,18.0,-4.7,-4.9,-5.5,-5.6$.

HRMS (UPLC-MS) $m / z$ calcd. for $\left(\mathrm{C}_{27} \mathrm{H}_{44} \mathrm{~N}_{4} \mathrm{O}_{7} \mathrm{Si}_{2} \mathrm{Na}\right)^{+}(\mathrm{M}+\mathrm{Na})^{+}=615.2646$, found $m / z=615.2646$.<smiles>O=c1[nH]/c(=N\Oc2ccc([N+](=O)[O-])cc2)ccn1OC1COCC1O</smiles>

Compound 5a (432 mg, $0.73 \mathrm{mmol}$ ) was dissolved in THF ( $3 \mathrm{~mL}$ ). While stirring, Et ${ }_{3} \mathrm{~N} \cdot 3 \mathrm{HF}$ (450 mg, 3.0 mmol) was slowly added. The reaction was stirred at $25^{\circ} \mathrm{C}$ overnight. The reaction was concentrated under vacuum and purified by flash chromatography on a silica column. Elution with $10 \% \mathrm{MeOH}$ in DCM gave 6a as a yellow solid (173 mg, 65\%). ${ }^{1} \mathrm{H}$ NMR (400 MHz, $d_{6}$-DMSO) $\delta 11.1(\mathrm{~s}, 1 \mathrm{H}), 8.23(\mathrm{~d}, J=9.2 \mathrm{~Hz}, 2 \mathrm{H})$, $7.43(\mathrm{~d}, J=8.4 \mathrm{~Hz}, 1 \mathrm{H}), 7.37(\mathrm{~d}, J=9.2 \mathrm{~Hz}, 2 \mathrm{H}), 6.19$ (t, $J=6.8 \mathrm{~Hz}, 1 \mathrm{H}), 5.80(\mathrm{~d}, J=8.4 \mathrm{~Hz}, 1 \mathrm{H}), 5.28(\mathrm{~d}$, $J=4.0 \mathrm{~Hz}, 1 \mathrm{H}), 5.03(\mathrm{~d}, J=5.2 \mathrm{~Hz}, 1 \mathrm{H}), 4.26-4.22(\mathrm{~m}, 1 \mathrm{H}), 3.77(\mathrm{dd}, J=2.8,4.0 \mathrm{~Hz}, 1 \mathrm{H}), 3.57-3.53(\mathrm{~m}$, 2H), 2.08 - $2.04(\mathrm{~m}, 2 \mathrm{H}) .{ }^{13} \mathrm{C}$ NMR (101 MHz, $d_{6}$-DMSO) $\delta 164.2,149.3,149.2,141.5,134.4,126.2,114.5$, 105.0, 96.5, 87.6, 84.1, 71.0, 61.9.

HRMS (UPLC-MS) $m / z$ calcd for $\left(\mathrm{C}_{15} \mathrm{H}_{16} \mathrm{~N}_{4} \mathrm{O}_{7} \mathrm{Na}\right)^{+}(\mathrm{M}+\mathrm{Na})^{+}=387.0917$, found $m / z=387.0908$.

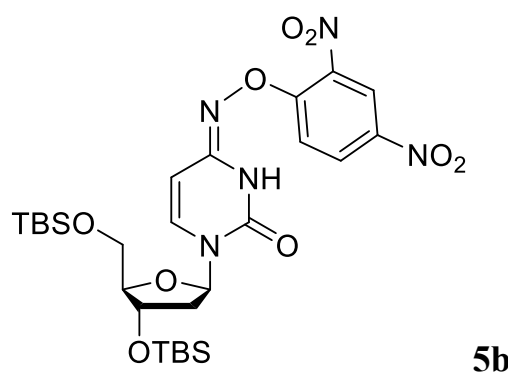

Compound 4 (70.7 mg, $0.15 \mathrm{mmol})$ was added to THF $(1 \mathrm{~mL})$. The reaction mixture was cooled to $0{ }^{\circ} \mathrm{C}$ and treated with $\mathrm{NaH}$ ( $40 \%$ dispersion in mineral oil, $18 \mathrm{mg}, 0.3 \mathrm{mmol}$ ) under $\mathrm{N}_{2}$. The mixture was allowed to warm to room temperature over $1 \mathrm{~h}$, then 2,4-dinitro-fluorobenzene ( $33.5 \mathrm{mg}, 0.18 \mathrm{mmol}$ ) was added and the mixture was warmed to $60{ }^{\circ} \mathrm{C}$ and stirred for $4 \mathrm{~h}$. The mixture was cooled to room temperature and diluted with $\mathrm{H}_{2} \mathrm{O}$ and EtOAc. The layers were separated and the aqueous layer was extracted with EtOAc $(10 \mathrm{~mL} \times 3)$. The combined organic layers were dried $\left(\mathrm{MgSO}_{4}\right)$, filtered and evaporated to dryness under reduced pressure. The crude product was purified by column chromatography (Hex/EtOAc, 9:1 to 3:1) to yield $\mathbf{5 b}$ as a yellow solid (60.2 mg, 63\%). ${ }^{1} \mathrm{H} \mathrm{NMR}\left(400 \mathrm{MHz}, \mathrm{CDCl}_{3}\right) \delta 8.91(\mathrm{~d}, J=2.8 \mathrm{~Hz}, 1 \mathrm{H}), 8.47$ (s, $1 \mathrm{H}), 8.42(\mathrm{dd}, J=2.8,9.6 \mathrm{~Hz}, 1 \mathrm{H}), 7.98(\mathrm{~d}, J=9.2 \mathrm{~Hz}, 1 \mathrm{H}), 7.55$ (d, $J=8.4 \mathrm{~Hz}, 1 \mathrm{H}), 6.27$ (t, $J=6.4 \mathrm{~Hz}$, $1 \mathrm{H}), 5.68(\mathrm{~d}, J=8.4 \mathrm{~Hz}, 1 \mathrm{H}), 4.47-4.42(\mathrm{~m}, 1 \mathrm{H}), 3.96-3.88(\mathrm{~m}, 2 \mathrm{H}), 3.78(\mathrm{t}, J=8.4 \mathrm{~Hz}, 1 \mathrm{H}), 2.26-2.24$ $(\mathrm{m}, 1 \mathrm{H}), 2.09-2.02(\mathrm{~m}, 1 \mathrm{H}), 0.94(\mathrm{~s}, 9 \mathrm{H}), 0.89(\mathrm{~s}, 9 \mathrm{H}), 0.12(\mathrm{~s}, 6 \mathrm{H}), 0.08(\mathrm{~s}, 6 \mathrm{H}) .{ }^{13} \mathrm{C} \mathrm{NMR}(101 \mathrm{MHz}$, $\left.\mathrm{CDCl}_{3}\right) \delta 157.0,150.3,147.6,140.5,135.4,134.7,129.9,122.4,117.0,95.3,87.7,84.9,71.5,62.6,41.4$, $25.9,25.8,25.7,25.6,18.4,-4.6,-4.9,-5.4,-5.6$. 
HRMS (UPLC-MS) $m / z$ calcd. for $\left(\mathrm{C}_{27} \mathrm{H}_{43} \mathrm{~N}_{5} \mathrm{O}_{9} \mathrm{Si}_{2} \mathrm{Na}\right)^{+}(\mathrm{M}+\mathrm{Na})^{+}=637.2599$, found $m / z=637.2608$.<smiles>O=c1[nH]/c(=N\Oc2ccc([N+](=O)[O-])cc2[N+](=O)[O-])ccn1C1CC(O)CO1</smiles>

6b

Compound 5b (60.2 mg, $0.095 \mathrm{mmol})$ was dissolved in THF (0.7 mL). Et ${ }_{3} \mathrm{~N} \cdot 3 \mathrm{HF}$ (56.4 mg, $\left.0.35 \mathrm{mmol}\right)$ was slowly added. The reaction mixture was stirred at room temperature overnight. The reaction was concentrated under vacuum and purified by flash chromatography on a silica column. Elution with $10 \%$ $\mathrm{MeOH}$ in DCM gave $6 \mathbf{b}$ as a yellow solid (31.5 mg, 81\%). ${ }^{1} \mathrm{H}$ NMR (400 MHz, $d_{6}$-DMSO) $\delta 11.43$ (d, $J=$ $2.4 \mathrm{~Hz}, 0.3 \mathrm{H}), 10.92$ (d, $J=2.4 \mathrm{~Hz}, 0.7 \mathrm{H}), 8.80$ (d, $J=2.8 \mathrm{~Hz}, 0.3 \mathrm{H}), 8.72(\mathrm{~d}, J=2.8 \mathrm{~Hz}, 0.6 \mathrm{H}), 8.58$ (dd, $J=2.8,9.2 \mathrm{~Hz}, 0.3 \mathrm{H}), 8.49(\mathrm{dd}, J=2.8,9.2 \mathrm{~Hz}, 0.7 \mathrm{H}), 7.85(\mathrm{~d}, J=9.2 \mathrm{~Hz}, 0.3 \mathrm{H}), 7.75(\mathrm{~d}, J=9.2 \mathrm{~Hz}, 0.7 \mathrm{H})$, $7.68(\mathrm{~d}, J=8.4 \mathrm{~Hz}, 0.3 \mathrm{H}), 7.54(\mathrm{~d}, J=8.4 \mathrm{~Hz}, 0.7 \mathrm{H}), 6.21-6.13(\mathrm{~m}, 1.4 \mathrm{H}), 5.87(\mathrm{dd}, J=2.0,8.4 \mathrm{~Hz}, 0.7 \mathrm{H})$, $5.27(\mathrm{t}, J=4.0 \mathrm{~Hz}, 1.0 \mathrm{H}), 5.03(\mathrm{t}, J=4.8 \mathrm{~Hz}, 1.0 \mathrm{H}), 4.26-4.22(\mathrm{~m}, 1 \mathrm{H}), 3.78$ (dd, $J=4.0 \mathrm{~Hz}, 8.4 \mathrm{~Hz}, 1 \mathrm{H})$, $3.57(\mathrm{dd}, J=4.4,8.4 \mathrm{~Hz}, 2 \mathrm{H}), 2.10-2.06(\mathrm{~m}, 2 \mathrm{H}) .{ }^{13} \mathrm{C}$ NMR (101 MHz, $d_{6}$-DMSO) $\delta 157.6,156.9,156.3$, 152.0, 149.0, 148.9, 140.2, 139.9, 138.1, 136.6, 135.7, 135.6, 130.8, 130.2, 122.4, 122.1, 116.9, 116.7, 95.6, $91.5,87.8,87.7,84.5,84.4,70.9,70.8,61.8$.

HRMS (UPLC-MS) $m / z$ calcd. for $\left(\mathrm{C}_{15} \mathrm{H}_{15} \mathrm{~N}_{5} \mathrm{O}_{9} \mathrm{Na}\right)^{+}(\mathrm{M}+\mathrm{Na})^{+}=410.0948$, found $m / z=410.0938$.

Preparation of precursor phosphoramidite.<smiles>O=c1[nH]c(=NOc2ccc([N+](=O)[O-])cc2)ccn1C1CCOCC1O</smiles>

Compound 6a (182mg, $0.5 \mathrm{mmol})$, was azeotropically dried with pyridine $(2 \mathrm{~mL})$ three times. Pyridine (2 $\mathrm{mL})$, DMAP (6.1 mg, $0.05 \mathrm{mmol})$ and DMTCl $(220 \mathrm{mg}, 0.65 \mathrm{mmol})$ were added. The reaction was stirred at room temperature overnight. The reaction was concentrated under vacuum, and purified by flash chromatography (50\% ethyl acetate in DCM) on a silica column to give 29a as a yellow foam (259 mg, 78\%). ${ }^{1} \mathrm{H}$ NMR (400 MHz, $\left.\mathrm{CD}_{3} \mathrm{CN}\right) \delta .9 .47(\mathrm{~s}, 1 \mathrm{H}), 8.58(\mathrm{~d}, J=4.4 \mathrm{~Hz}, 2 \mathrm{H}), 8.21(\mathrm{~d}, J=9.2 \mathrm{~Hz}, 2 \mathrm{H}), 7.72$ - $7.68(\mathrm{~m}, 1 \mathrm{H}), 7.44-7.41(\mathrm{~m}, 2 \mathrm{H}), 7.34-7.25(\mathrm{~m}, 14 \mathrm{H}), 6.87(\mathrm{~d}, J=8.4 \mathrm{~Hz}, 4 \mathrm{H}), 6.44(\mathrm{t}, J=7.2 \mathrm{~Hz}, 1 \mathrm{H})$, $5.47(\mathrm{~d}, J=8.0 \mathrm{~Hz}, 1 \mathrm{H}), 4.65-4.62(\mathrm{~m}, 1 \mathrm{H}), 4.11-4.09(\mathrm{~m}, 1 \mathrm{H}), 3.80(\mathrm{~s}, 6 \mathrm{H}), 3.49-3.45-3.38(\mathrm{~m}, 2 \mathrm{H})$, $2.43-2.37(\mathrm{~m}, 1 \mathrm{H}), 2.33-2.26(\mathrm{~m}, 1 \mathrm{H}) .{ }^{13} \mathrm{C} \mathrm{NMR}\left(101 \mathrm{MHz}, \mathrm{CD}_{3} \mathrm{CN}\right) \delta$ 163.6, 158.7, 149.4, 149.3, 147.9, 144.4, 142.0, 135.4, 135.3, 132.8, 130.2, 130.1, 128.1, 128.0, 127.1, 125.7, 114.0, 113.3, 97.2, 86.9, 86.1, $84.3,72.0,63.4,55.2,40.3$.

HRMS (UPLC-MS) $m / z$ calcd. for $\left(\mathrm{C}_{36} \mathrm{H}_{34} \mathrm{~N}_{4} \mathrm{O}_{9} \mathrm{Na}\right)^{+}(\mathrm{M}+\mathrm{Na})^{+}=689.2223$, found $m / z=689.2219$. 


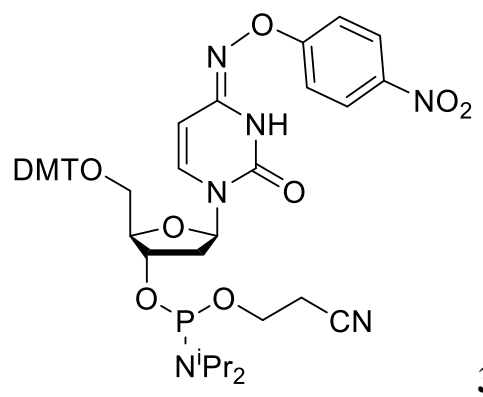

DIPEA (64.5 mg, $0.5 \mathrm{mmol})$ and DCM (10 mL) were added to 29a ( $84 \mathrm{mg}, 0.13 \mathrm{mmol})$. The reaction was stirred at $0{ }^{\circ} \mathrm{C}$, and 2-cyanoethyl $\mathrm{N}, \mathrm{N}$-diisopropylchloro-phosphoramidite $(37.5 \mathrm{mg}, 0.16 \mathrm{mmol}$ ) was added dropwise. The reaction was stirred at room temperature for $30 \mathrm{~min}$. The reaction was concentrated under vacuum, and purified by flash chromatography (ethyl acetate : hexane : triethylamine $=45: 50: 5$ ) on a silica column to give 30a as light yellow foam (71 mg, 63\%). ${ }^{1} \mathrm{H}$ NMR (400 MHz, $\left.\mathrm{CD}_{3} \mathrm{CN}\right): \delta 9.22(\mathrm{~s}, 1 \mathrm{H})$, $8.21(\mathrm{~d}, J=1.2 \mathrm{~Hz}, 2 \mathrm{H}), 7.47$ (dd, $J=5.6,7.2 \mathrm{~Hz}, 2 \mathrm{H}), 7.35$ (m, 8H), 7.24 (m, 2H), 6.89 (dd, $J=5.6,9.2$ $\mathrm{Hz}, 4 \mathrm{H}), 6.24$ (dd, $J=6.8,12.8 \mathrm{~Hz}, 1 \mathrm{H}), 5.53(\mathrm{dd}, J=3.2,9.6 \mathrm{~Hz}, 1 \mathrm{H}), 4.67$ - $4.61(\mathrm{~m}, 1 \mathrm{H}), 3.78(\mathrm{~s}, 3 \mathrm{H})$, $3.77(\mathrm{~s}, 3 \mathrm{H}), 3.69-3.63(\mathrm{~m}, 4 \mathrm{H}), 3.47-3.43(\mathrm{~m}, 2 \mathrm{H}), 2.66(\mathrm{t}, J=5.6 \mathrm{~Hz}, 1 \mathrm{H}), 2.55(\mathrm{t}, J=2.54 \mathrm{~Hz}, 1 \mathrm{H})$, $1.18(\mathrm{~d}, J=6.8 \mathrm{~Hz}, 9 \mathrm{H}), 1.08(\mathrm{~d}, J=7.2 \mathrm{~Hz}, 3 \mathrm{H}) .{ }^{13} \mathrm{C} \mathrm{NMR}\left(101 \mathrm{MHz}, \mathrm{CD}_{3} \mathrm{CN}\right) \delta 163.6,158.7,158.6$, 149.5, 149.3 148.0, 144.4, 142.1, 136.4, 135.5, 135.4, 132.9, 130.2, 130.1, 128.2, 128.0, 127.1, 125.8, 123.9, $114.1,113.2,97.1,86.9,86.1,84.4,71.7,63.4,55.2,40.4,29.7,22.7,14.1 .{ }^{31} \mathrm{P} \mathrm{NMR}\left(162 \mathrm{MHz}, \mathrm{CDCl}_{3}\right) \delta$ $148.0(\mathrm{~s})$.

HRMS (ESI-TOF) $m / z$ calcd. for $\left(\mathrm{C}_{45} \mathrm{H}_{52} \mathrm{~N}_{6} \mathrm{O}_{10} \mathrm{P}\right)^{+}(\mathrm{M}+\mathrm{H})^{+}=867.3483$, found $m / z=867.3493$. 

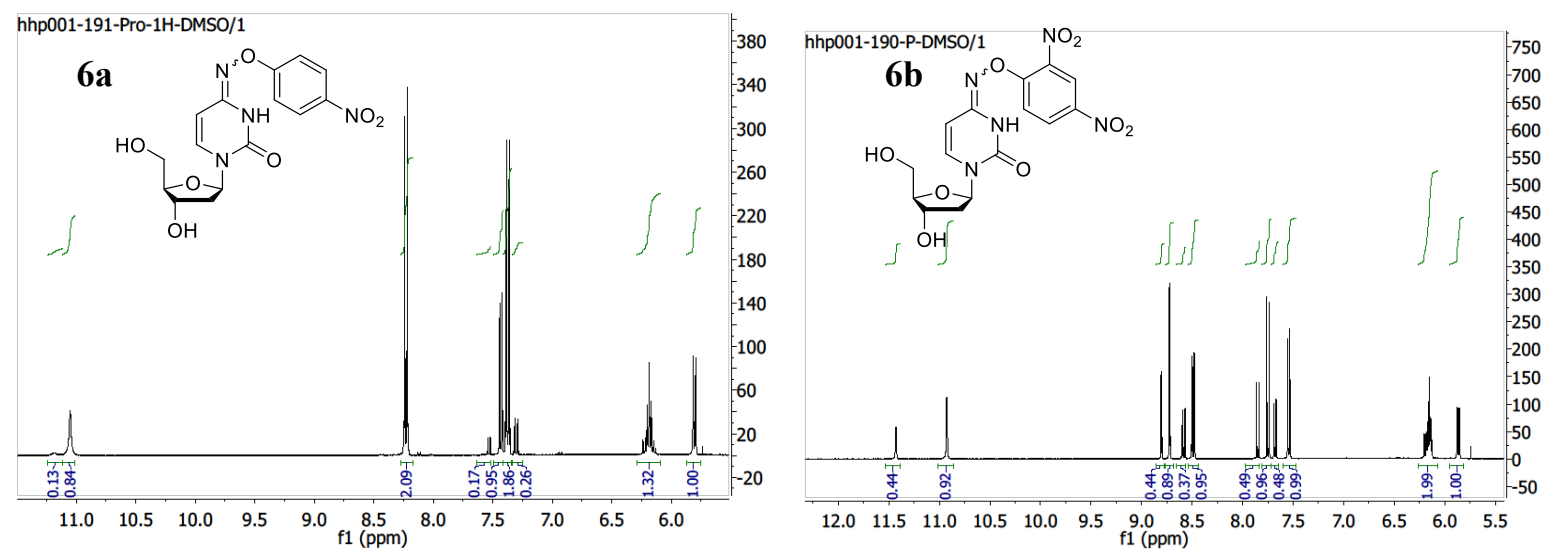

Figure S1. $E / Z$ isomer of $6 \mathbf{a}$ and $\mathbf{6 b}$ in $d_{6}$-DMSO. ${ }^{3}$
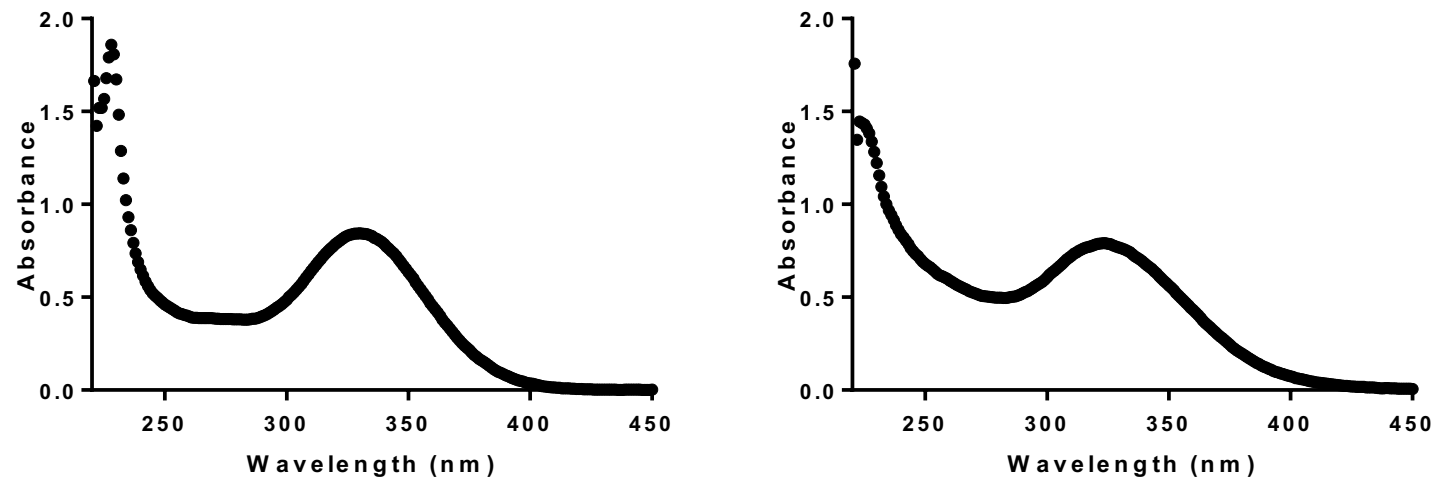

Figure S2. UV-VIS absorbance spectra of $6 \mathbf{a}($ Left, $40 \mu \mathrm{M}$ ) and $\mathbf{6 b}$ (Right, $40 \mu \mathrm{M}$ ).

Table S1. Retention times and response factors for HPLC analysis.

\begin{tabular}{ccc}
\hline Compound & Retention time & Response factor \\
\hline $\mathrm{dC}$ & $7.2 \mathrm{~min}$ & 1.65 \\
$\mathrm{dU}$ & $10.3 \mathrm{~min}$ & 1.00 \\
$\mathrm{~T}$ & $14.6 \mathrm{~min}$ & \\
$\mathbf{6 a}$ & $20.6 \mathrm{~min}$ & 1.08 \\
$\mathbf{6 b}$ & $20.7 \mathrm{~min}$ & 1.13 \\
\hline
\end{tabular}


Table S2. Photolysis of $6 \mathbf{6} / 6 \mathrm{~b}$ in anaerobic conditions. ${ }^{a, b}$

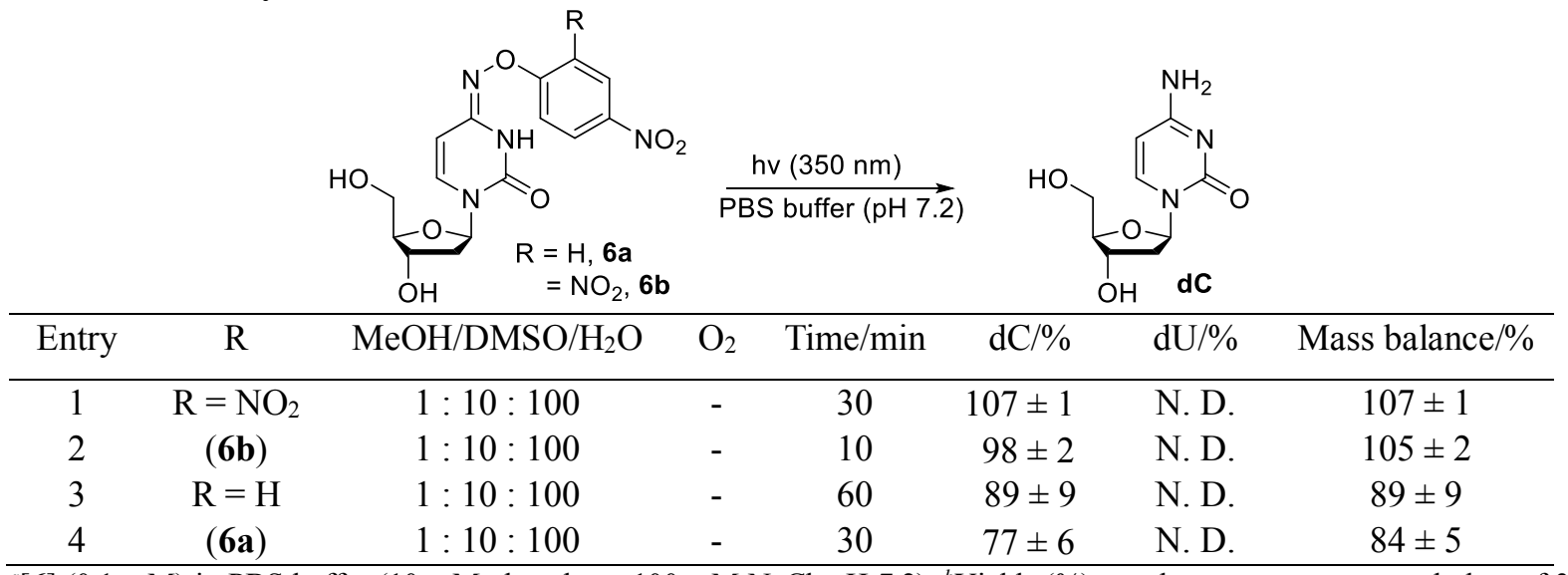

$\bar{a}[6](0.1 \mathrm{mM})$ in PBS buffer (10 mM phosphate, $100 \mathrm{mM} \mathrm{NaCl}, \mathrm{pH}$ 7.2). ${ }^{b}$ Yields (\%) are shown as average \pm std. dev. of 3 experiments using Thymidine $(0.1 \mathrm{mM})$ as internal standard. N. D., not detected.

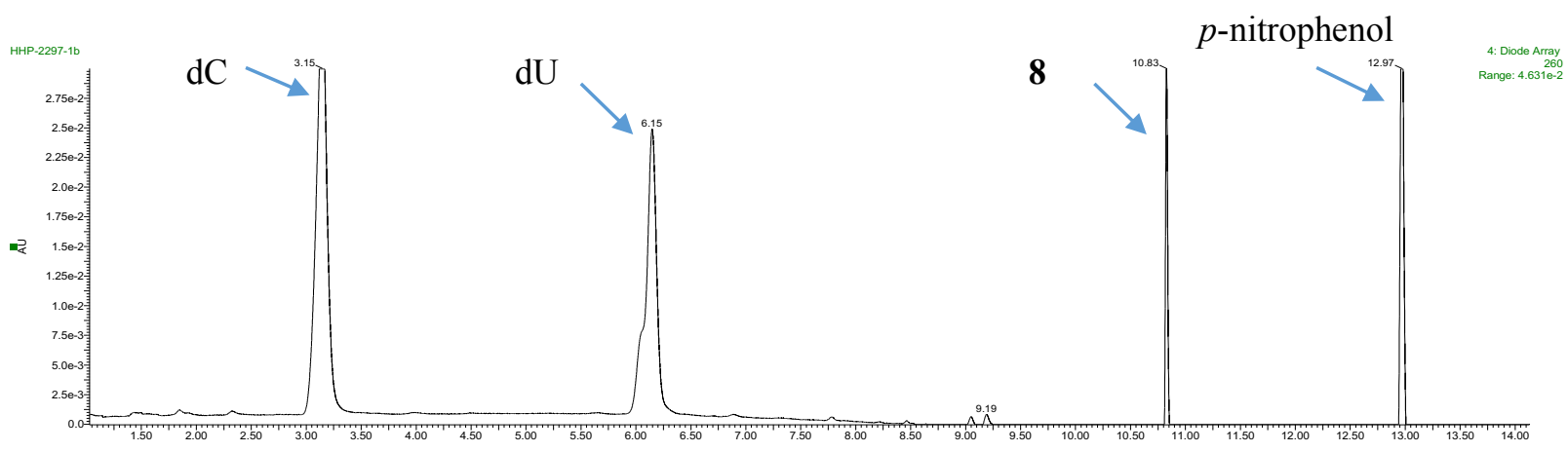

UV chromatogram $(\lambda=260 \mathrm{~nm})$ of the photolysate of $\mathbf{6 a}$.

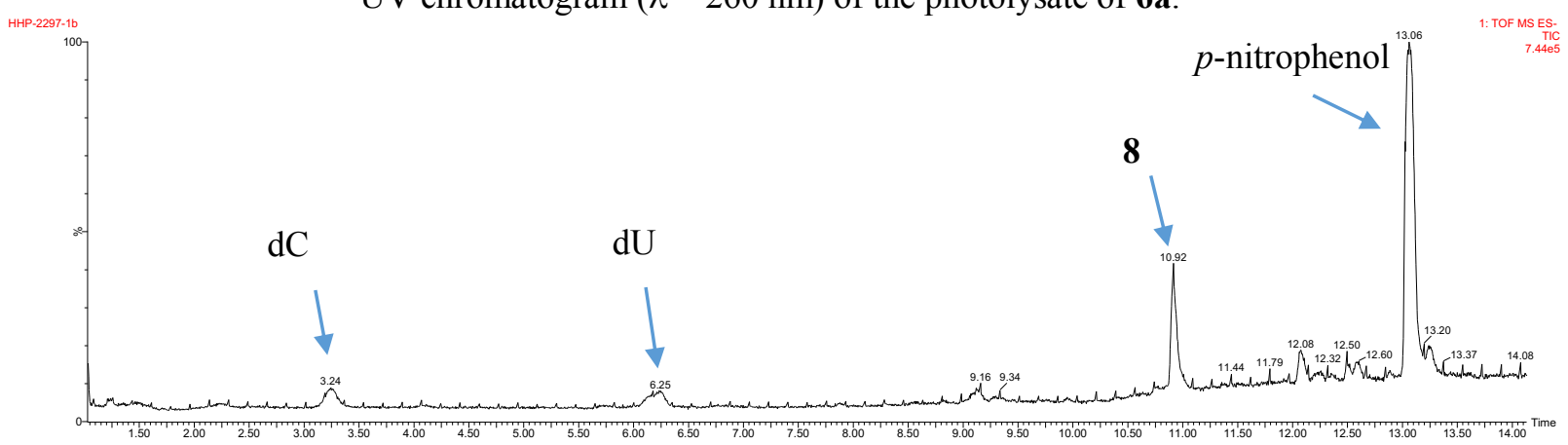

Figure S3. Total ion chromatogram (TIC) of the photolysate of 6a under aerobic conditions. [6a] $(0.1 \mathrm{mM})$ in PBS buffer (10 mM phosphate, $100 \mathrm{mM} \mathrm{NaCl}, \mathrm{pH} 7.2$. 
Scheme S1. Proposed mechanism for 7/8/8-OH formation after aerobic photolysis of 6 a.

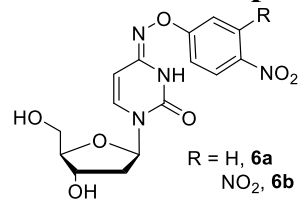

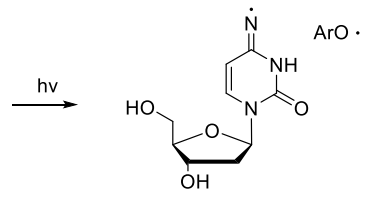

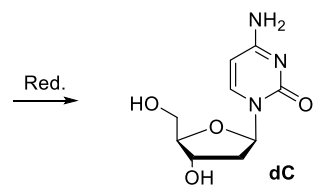

6a, $6 b$ or dC.

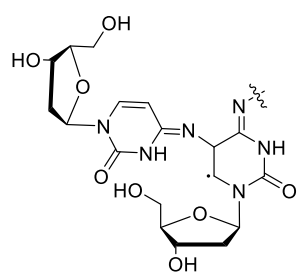

$\stackrel{\mathrm{O}_{2}}{\longrightarrow}$
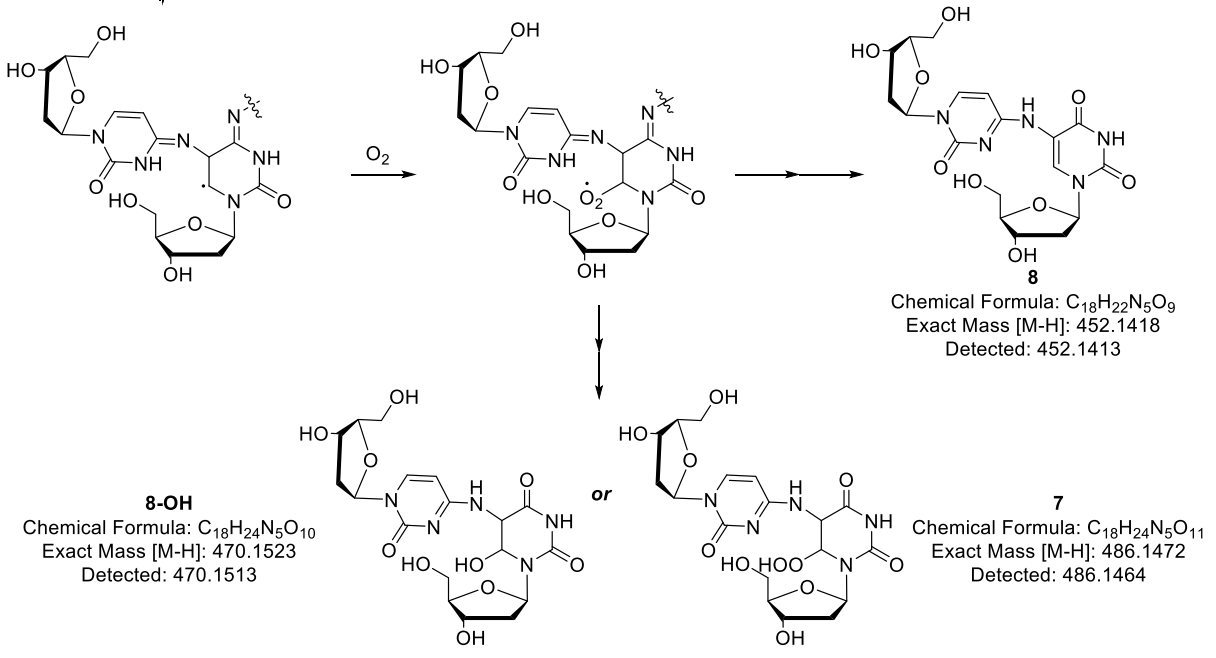

Chemical Formula: $\mathrm{C}_{18} \mathrm{H}_{22} \mathrm{~N}_{5} \mathrm{O}_{9}$ Exact Mass [M-H] : 452.1418 Detected: 452.1413 


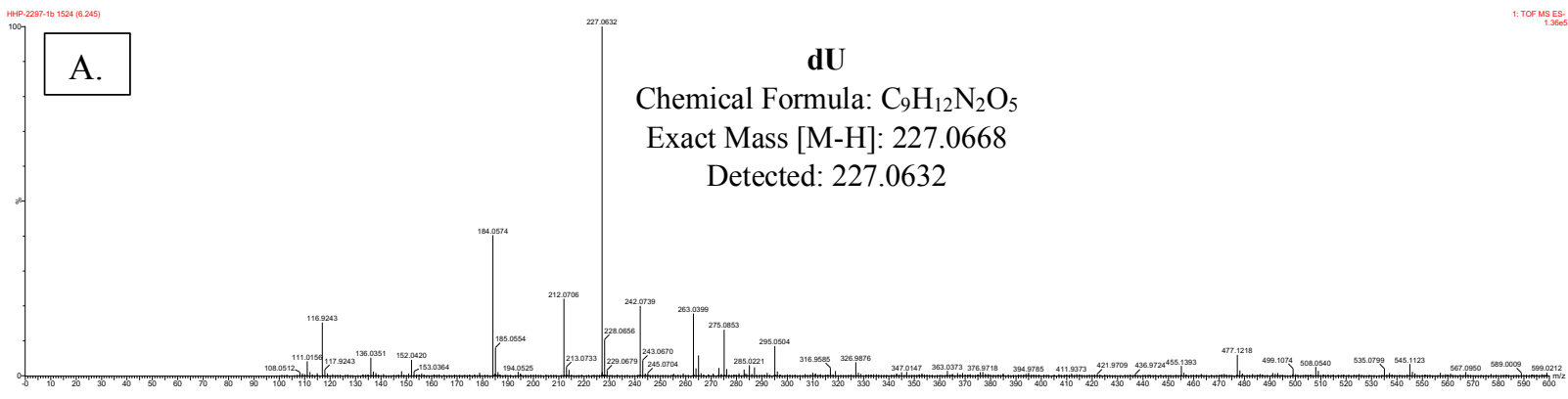

7
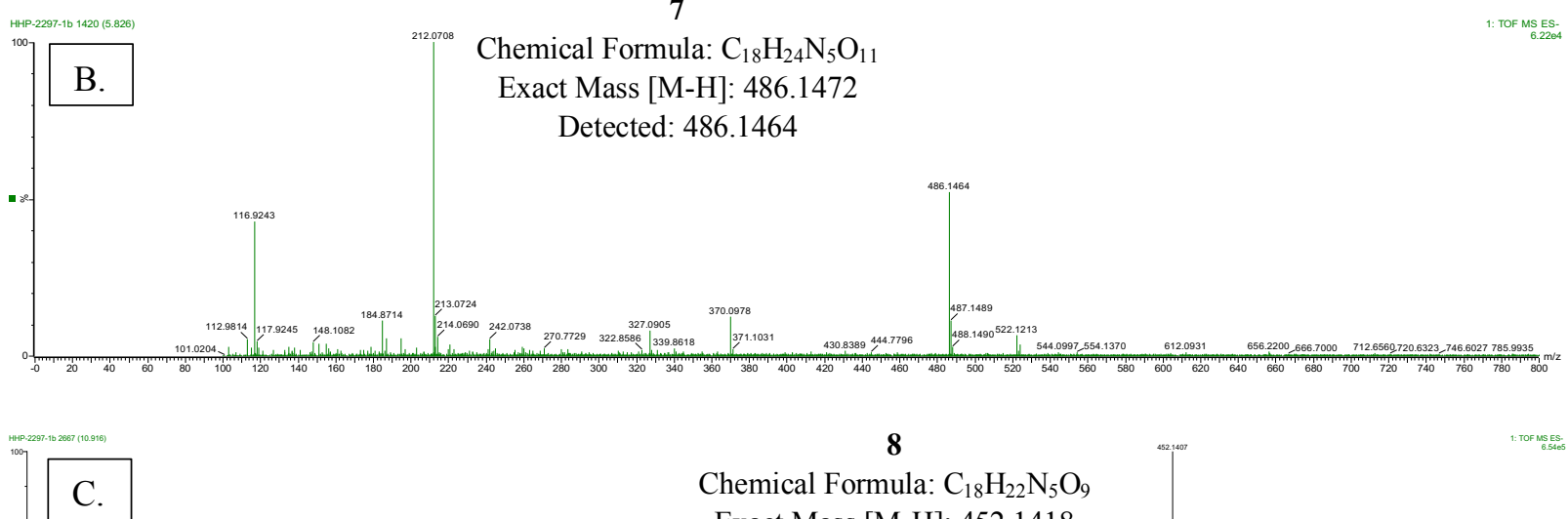

Chemical Formula: $\mathrm{C}_{18} \mathrm{H}_{22} \mathrm{~N}_{5} \mathrm{O}_{9}$

Exact Mass [M-H]: 452.1418

Detected: 452.1413
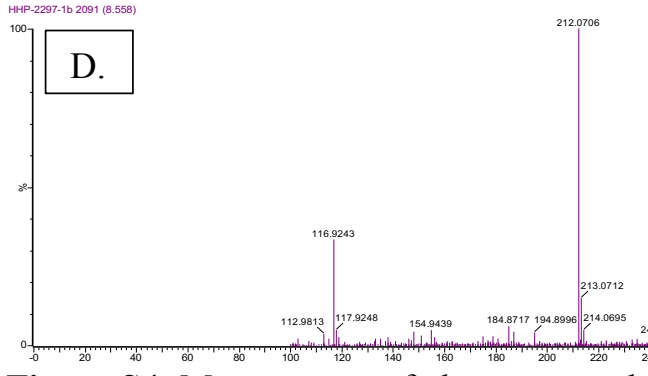

8-OH

1: ToF MS ES-

Chemical Formula: $\mathrm{C}_{18} \mathrm{H}_{24} \mathrm{~N}_{5} \mathrm{O}_{10}$

Exact Mass [M-H]: 470.1523

Detected: 470.1513

Figure S4. Mass spectra of chromatographic peaks from the aerobic photolysis of 6a. A. Ret. Time: 6.25 min B. Ret. Time: 5.83 min C. Ret. Time: 10.92 min D. Ret. Time: 8.56 min 
A. Aerobic photolysis of $\mathbf{6 a}(0.1 \mathrm{mM})$ without BME.

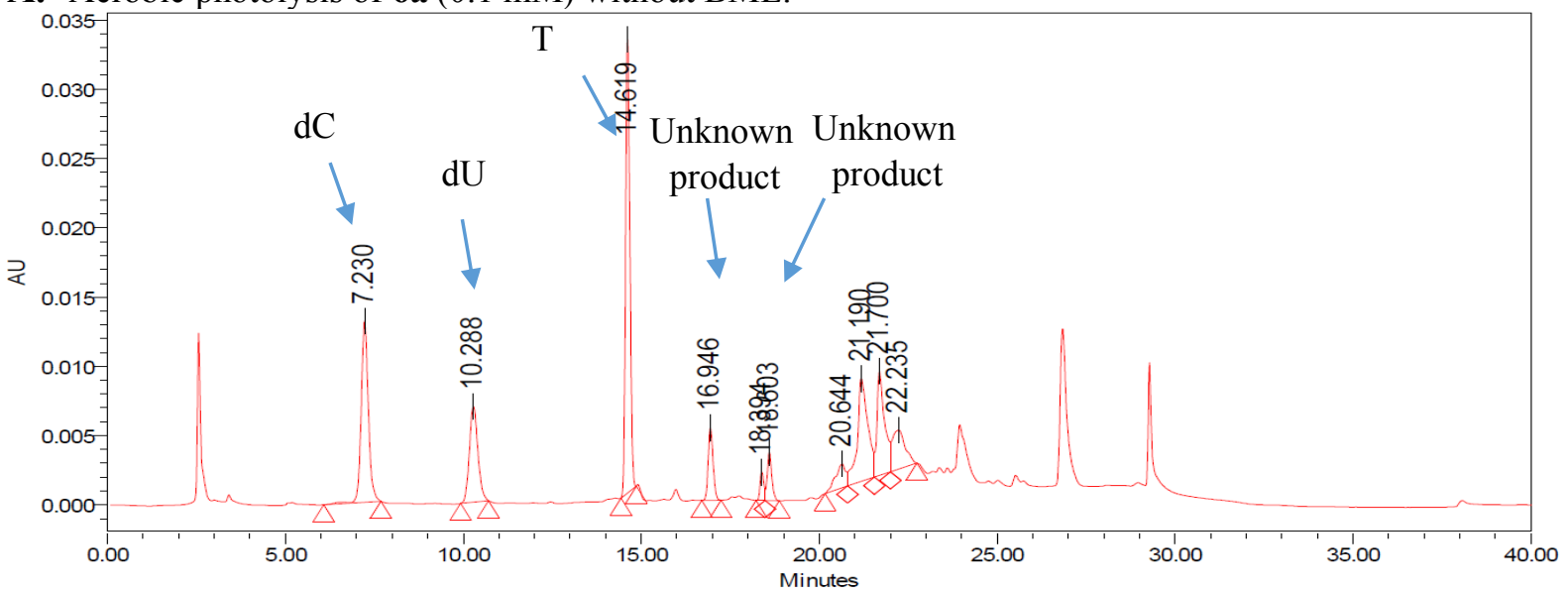

B. Aerobic photolysis of $6 \mathbf{6}(0.1 \mathrm{mM})$ with $1 \mathrm{mM}$ BME.

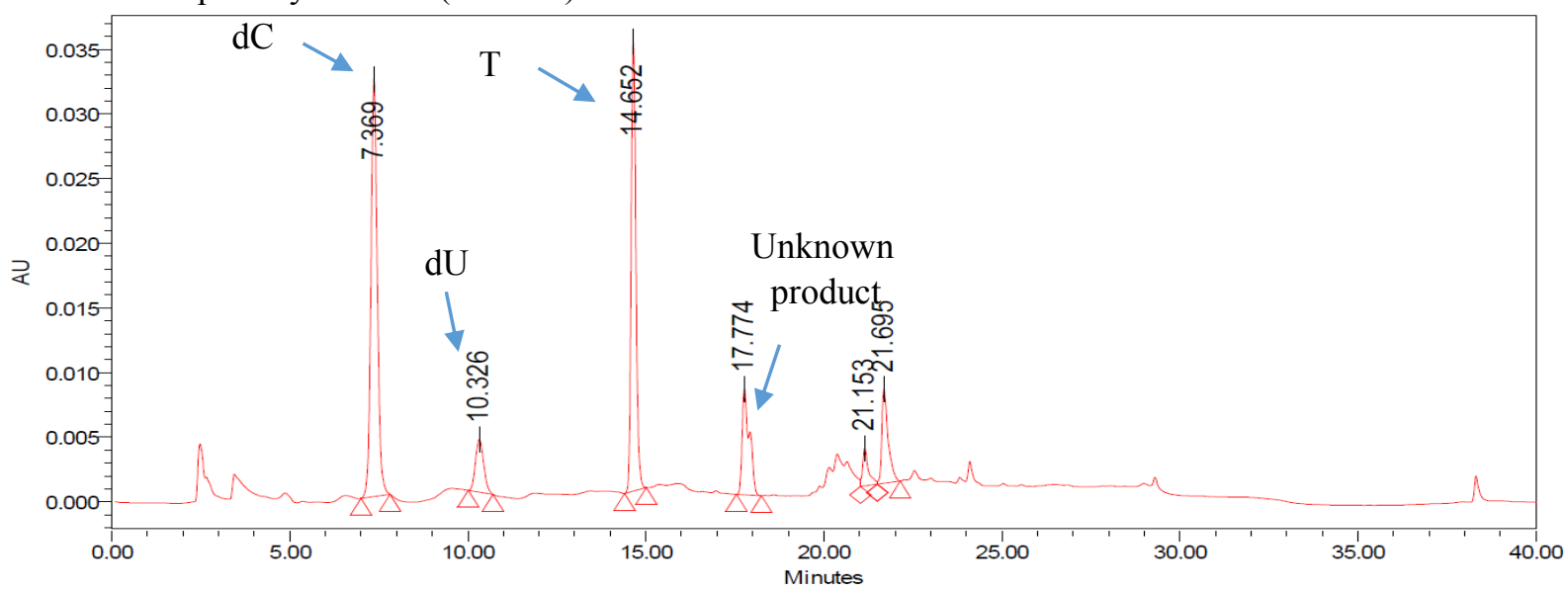

C. Aerobic photolysis of $\mathbf{6 a}(0.1 \mathrm{mM})$ with $10 \mathrm{mM}$ BME.

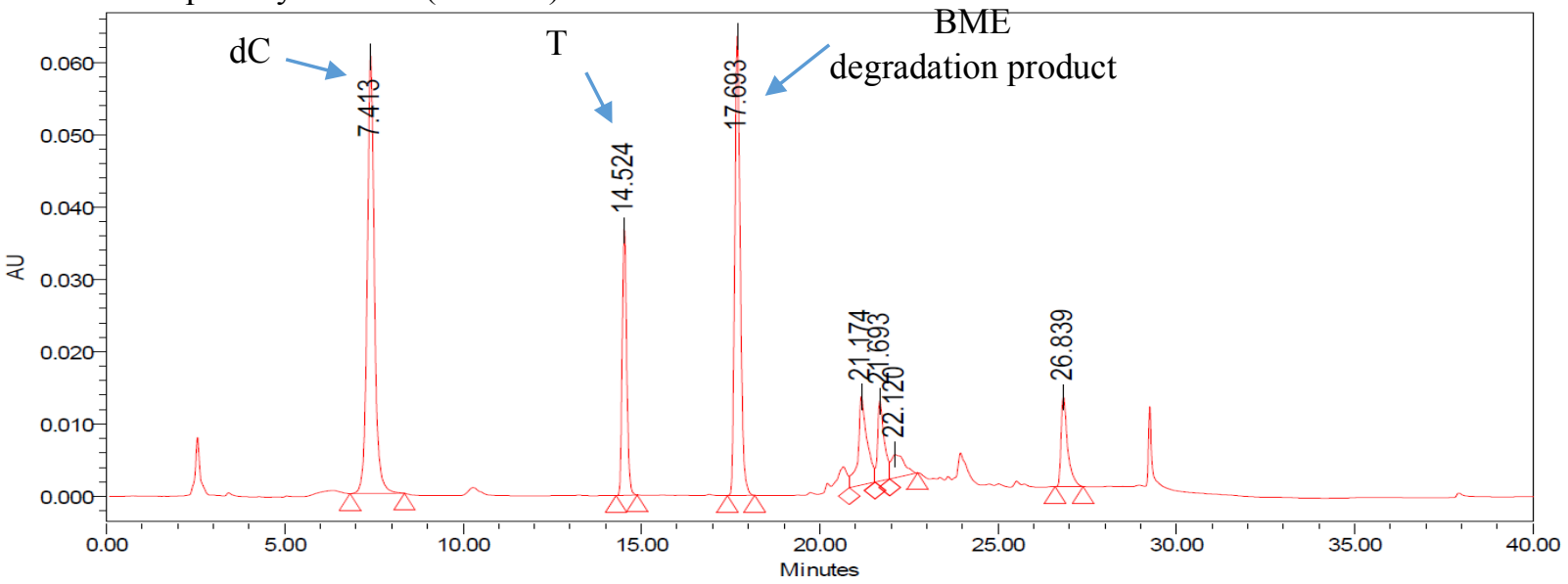


D. Anaerobic photolysis of $\mathbf{6 a}(0.1 \mathrm{mM})$ without BME.

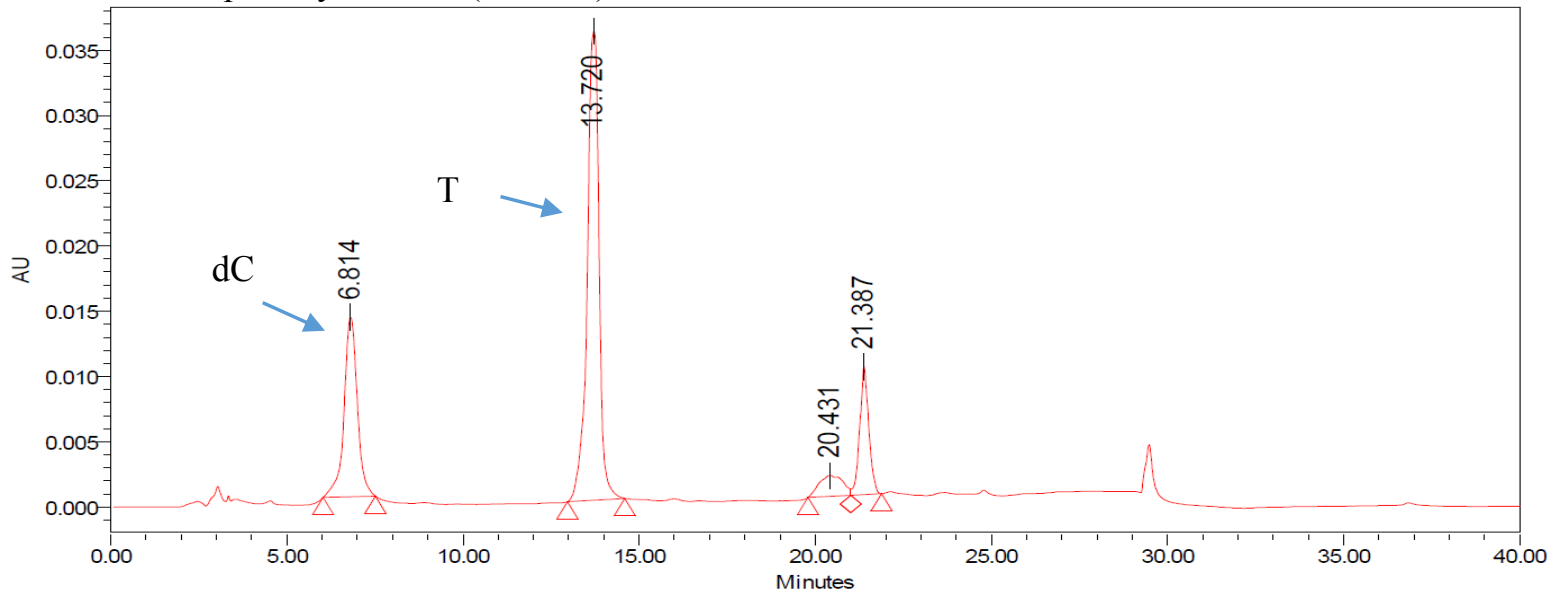

E. Anaerobic photolysis of $6 \mathbf{6}(0.1 \mathrm{mM})$ with $10 \mathrm{mM} \mathrm{BME}$.

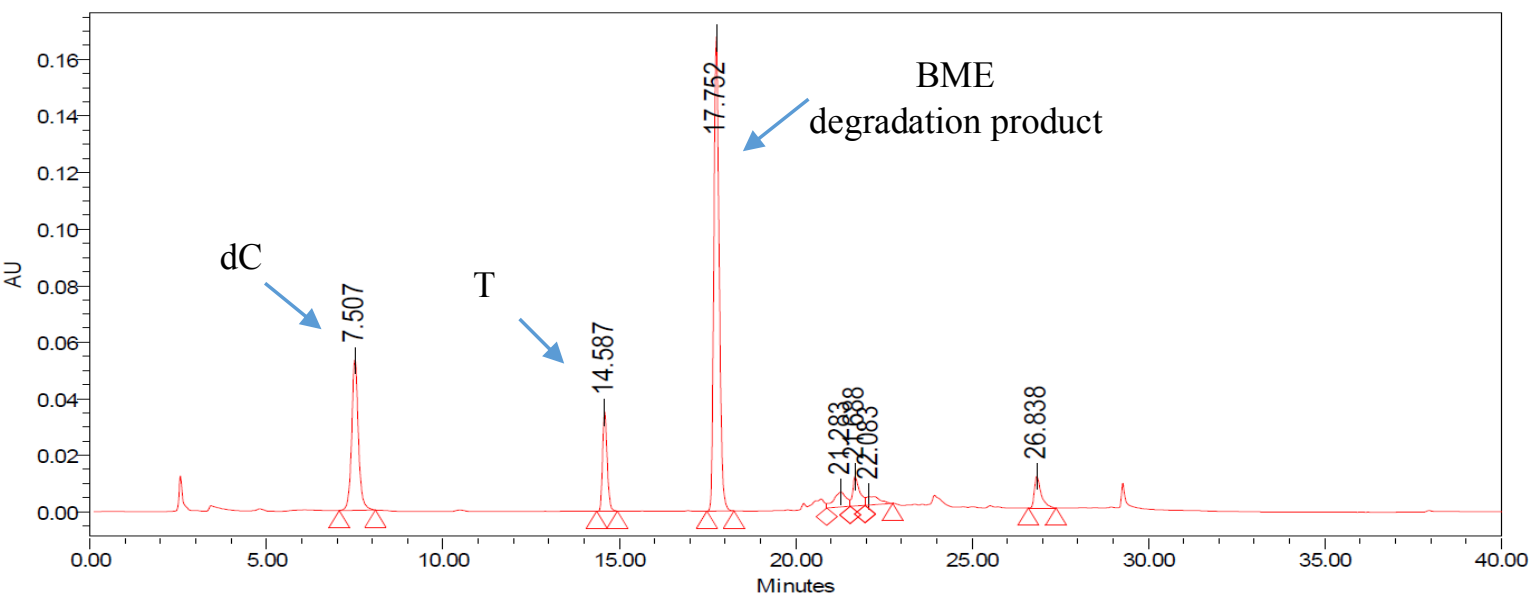

F. Aerobic photolysis of $\mathbf{6 b}(0.1 \mathrm{mM})$ without BME.

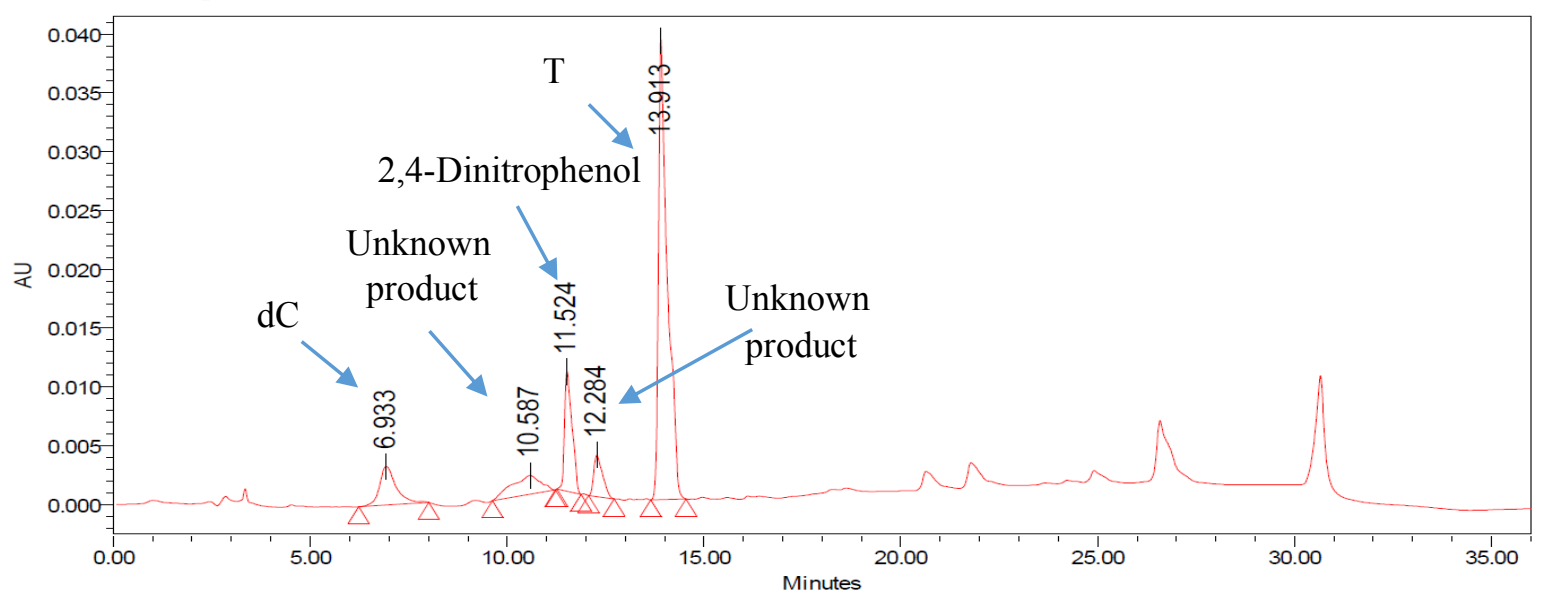


G. Anaerobic photolysis of $\mathbf{6 b}(0.1 \mathrm{mM})$ without BME.

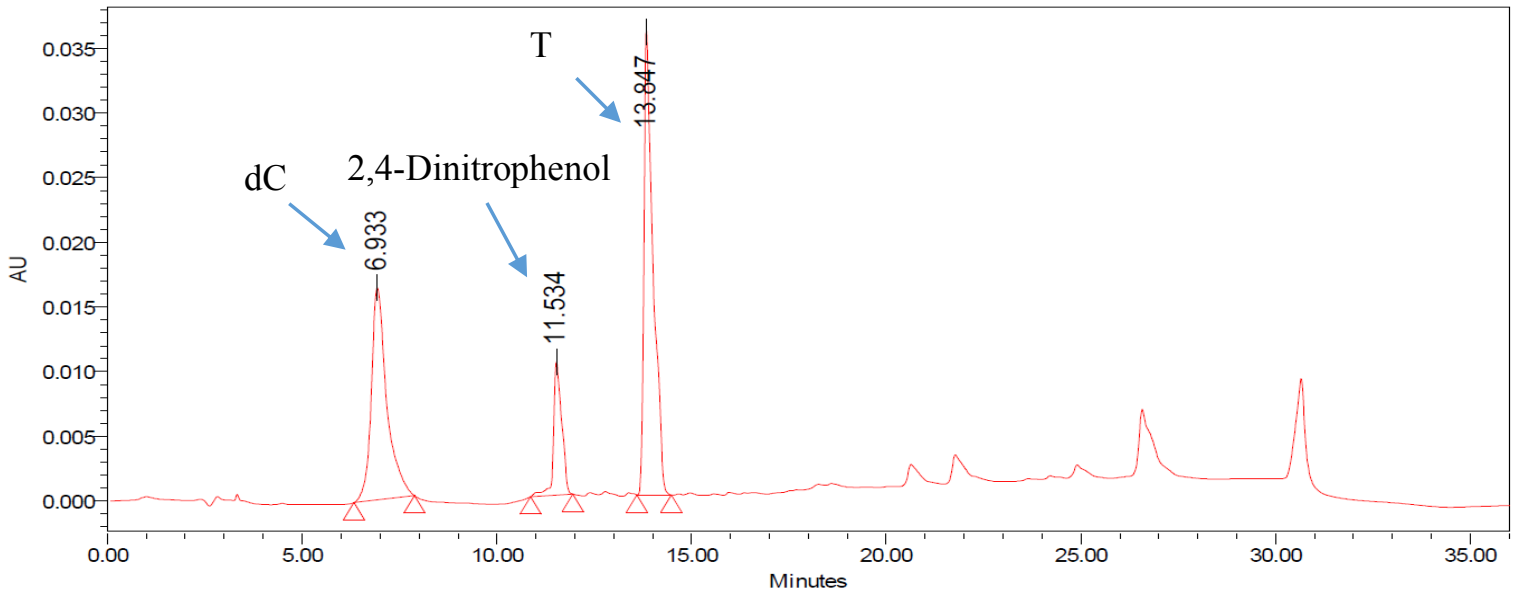

Figure S5. HPLC analysis of BME and $\mathrm{O}_{2}$ effect on the photolysis of $\mathbf{6 a} / \mathbf{6} \mathbf{b}$ using Thymidine (T, 0.05-0.1 $\mathrm{mM})$ as internal standard. A) Aerobic photolysis of $6 \mathbf{a}(0.1 \mathrm{mM})$ without BME; B) Aerobic photolysis of $6 \mathbf{6}$ $(0.1 \mathrm{mM})$ with $1 \mathrm{mM} \mathrm{BME}$; C) Aerobic photolysis of 6a $(0.1 \mathrm{mM})$ with $10 \mathrm{mM}$ BME; D) Anaerobic photolysis of 6a $(0.1 \mathrm{mM})$ without BME; E) Anaerobic photolysis of $6 \mathbf{6}(0.1 \mathrm{mM})$ with $10 \mathrm{mM}$ BME. F) Aerobic photolysis of $\mathbf{6 b}(0.1 \mathrm{mM})$ without BME; G) Anaerobic photolysis of $\mathbf{6 b}(0.1 \mathrm{mM})$ without BME. 

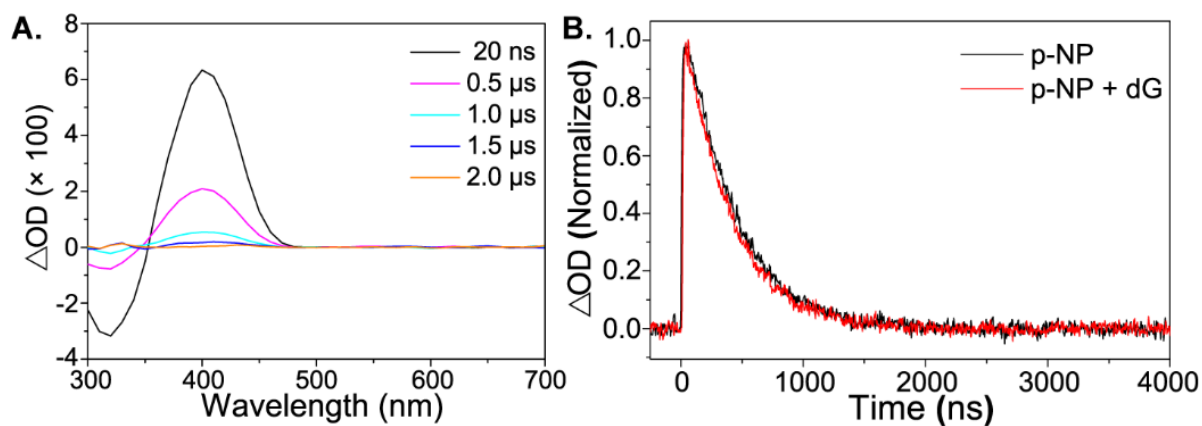

Figure S6. Time-resolved UV-VIS absorption spectra for $\mathrm{ArO} \bullet$ radical produced from excitation of $p$ nitrophenol. (A) Time-resolved UV-VIS absorption spectra for $355 \mathrm{~nm}$ laser photoexcitation of $p$ nitrophenol $(p-\mathrm{NP}, 50 \mu \mathrm{M})$ in aqueous buffer $(\mathrm{pH} 7.0)$ /acetonitrile $(1: 1, v: v)$ under anaerobic condition. (B) Kinetics traces of the $400 \mathrm{~nm}$ band after $355 \mathrm{~nm}$ laser photoexcitation of p-NP with and without dG (3 mM) under anaerobic condition. Note that $355 \mathrm{~nm}$ laser photoexcitation of $p$-NP can induce the photolysis of $p$ $\mathrm{NP}$ by $\mathrm{O}-\mathrm{H}$ bond breaking and produce pure $\mathrm{ArO} \bullet$ radical.
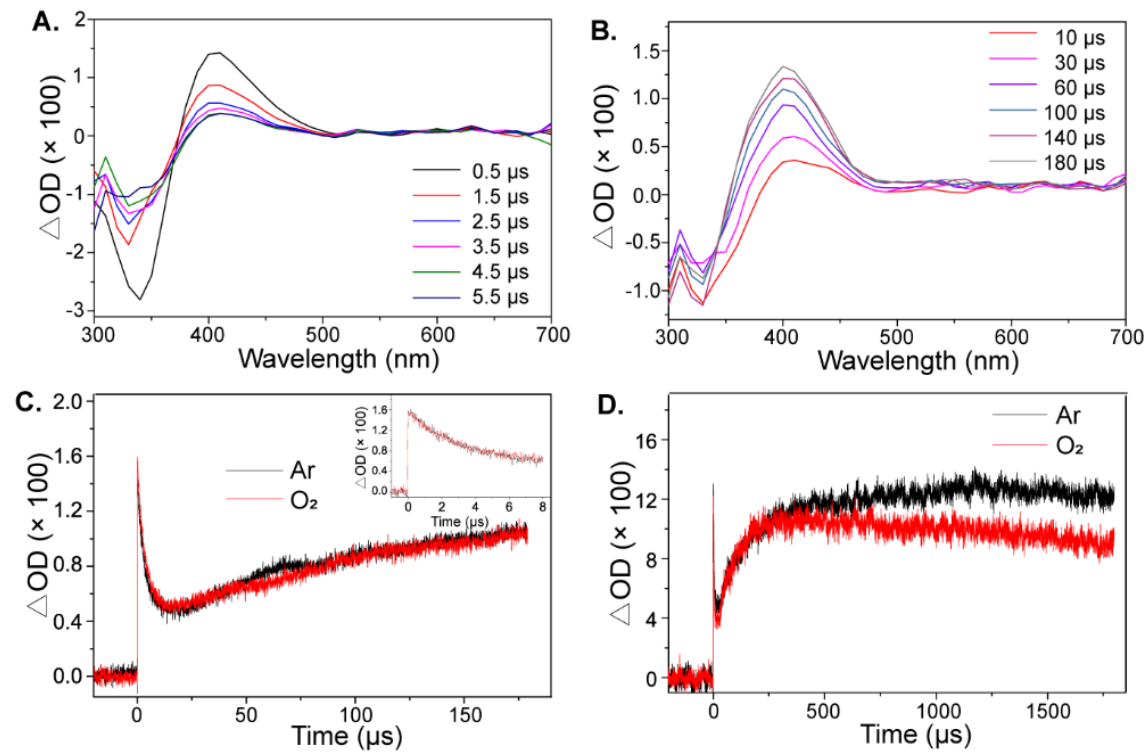

Figure S7. Time-resolved UV-vis absorption spectra for $355 \mathrm{~nm}$ laser photoexcitation of $\mathbf{6 b}(50 \mu \mathrm{M})$ in aqueous buffer $(\mathrm{pH} 7.0) /$ acetonitrile $(1: 1, v: v)$ under anaerobic condition at short (A) and long (B) timescale. Kinetics traces of the $400 \mathrm{~nm}$ band after $355 \mathrm{~nm}$ laser photoexcitation of $\mathbf{6 b}$ under anaerobic and aerobic condition at short $(\mathbf{C})$ and long (D) timescale.

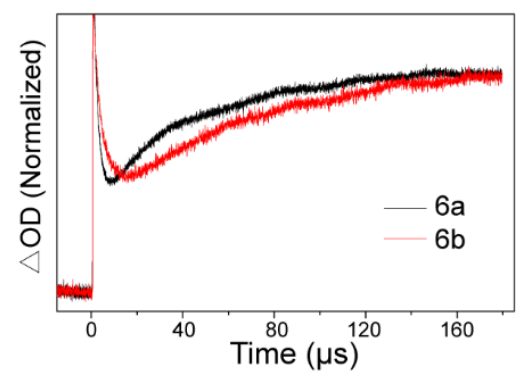

Figure S8. Kinetics traces of the $400 \mathrm{~nm}$ band after $355 \mathrm{~nm}$ laser photoexcitation of $6 \mathbf{a}(50 \mu \mathrm{M})$ or $6 \mathbf{b}(50$ $\mu \mathrm{M})$ in aqueous buffer $(\mathrm{pH} 7.0) /$ acetonitrile $(1: 1, v: v)$ under anaerobic condition. 

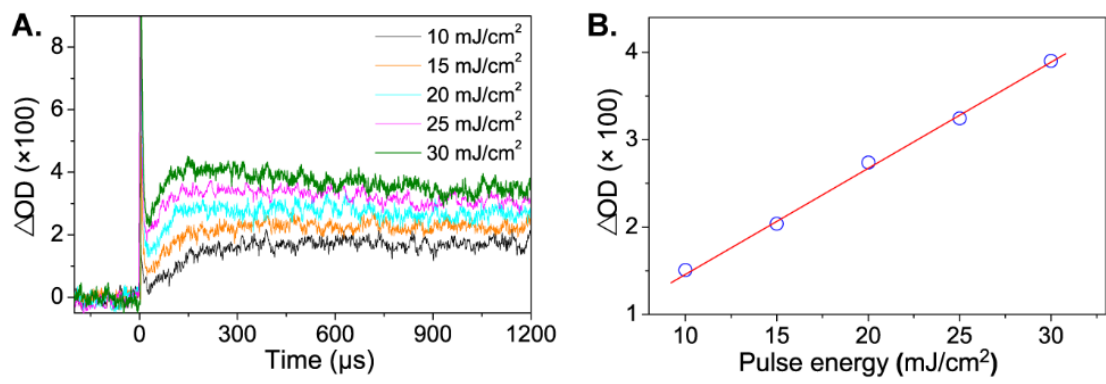

Figure S9. Effect of laser pulse energy on photolysis of 6a. (A) Kinetics traces of the $400 \mathrm{~nm}$ band obtained from photoexcitation of $\mathbf{6 a}$ at different $355 \mathrm{~nm}$ laser pulse energy. (B) Power dependence of the proposed biradical product yield (species 9 absorbing at $400 \mathrm{~nm}$ ) estimated from the absorbance at $220 \mu \mathrm{s}$. Red line is the linear fit.

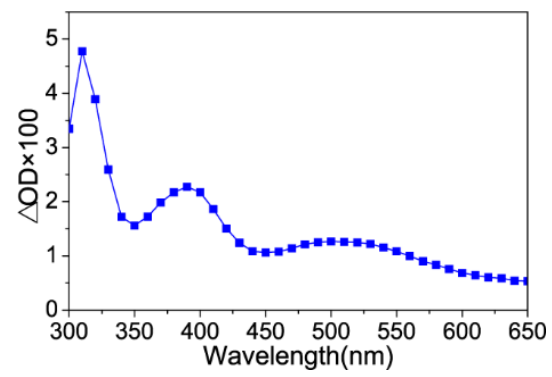

Figure S10. Transient absorption spectra of $\mathrm{dG} \bullet+/ \mathrm{dG}(-\mathrm{H}) \bullet$ obtained at $\mathrm{t}=500 \mathrm{~ns}$ after $355 \mathrm{~nm}$ laser flash photolysis of $\mathrm{Na}_{2} \mathrm{~S}_{2} \mathrm{O}_{8}(300 \mathrm{mM})+\mathrm{dG}(6 \mathrm{mM})$ in buffer $(\mathrm{pH} 7.0)$, where photolysis of $\mathrm{Na}_{2} \mathrm{~S}_{2} \mathrm{O}_{8}$ produces $\mathrm{SO}_{4}{ }^{-}$to oxidize $\mathrm{dG}$.

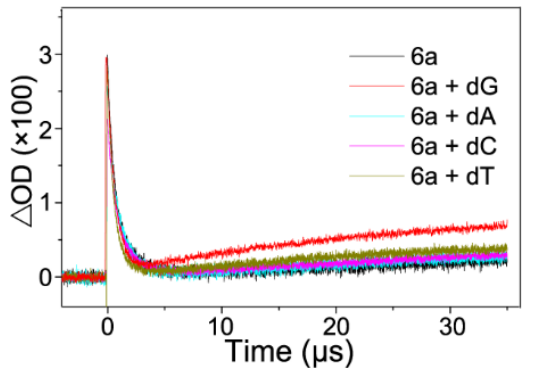

Figure S11. Kinetics traces of the $400 \mathrm{~nm}$ band after $355 \mathrm{~nm}$ laser photoexcitation of $\mathbf{6 a}, \mathbf{6 a}+\mathrm{dG}, \mathbf{6 a}+\mathrm{dA}$, $\mathbf{6 a}+\mathrm{dC}$, and $\mathbf{6 a}+\mathrm{dT}$ in aqueous buffer $(\mathrm{pH} 7.0) /$ acetonitrile $(1: 1, v: v)$ under anaerobic condition.

\section{Scheme S2. Conversion of ArO• into HO-ArO• ${ }^{4}$}<smiles>O=[N+]([O-])c1ccc(O)cc1</smiles><smiles>C=C1CC1C</smiles><smiles>O=[N+]([O-])c1ccc(O)cc1</smiles><smiles>CCCO</smiles><smiles>Oc1ccc(O)cc1</smiles> 


\section{5'-32P-GTC GCA ACG G $_{10} G_{11} T_{12}$ XAT CAC GTC GCT G-3' \\ 3'- CAG CGT TGC C C A GTA GTG CAG CGA C-5'}

\begin{tabular}{cccc}
\hline A. Sequence & Conditions & \multicolumn{2}{c}{ \% cleavage } \\
\cline { 3 - 4 } & & $\mathrm{dG}_{11}$ & $\mathrm{dT}_{12}$ \\
\hline & Pip $(1 \mathrm{M})$ & $20.7 \pm 0.9$ & $5.3 \pm 0.1$ \\
$5^{\prime}-\mathrm{G}_{9} \mathrm{G}_{10} \mathrm{G}_{11} \mathrm{~T}_{12} \mathrm{X}-3$, & Fpg & $18.1 \pm 1.1$ & N. D. \\
$(\mathrm{X}=\mathbf{6 a})$ & Pip $+0.7 \mathrm{M} \mathrm{BME}$ & $6.6 \pm 0.4$ & $15.2 \pm 1.1$ \\
\hline
\end{tabular}

B.

C.
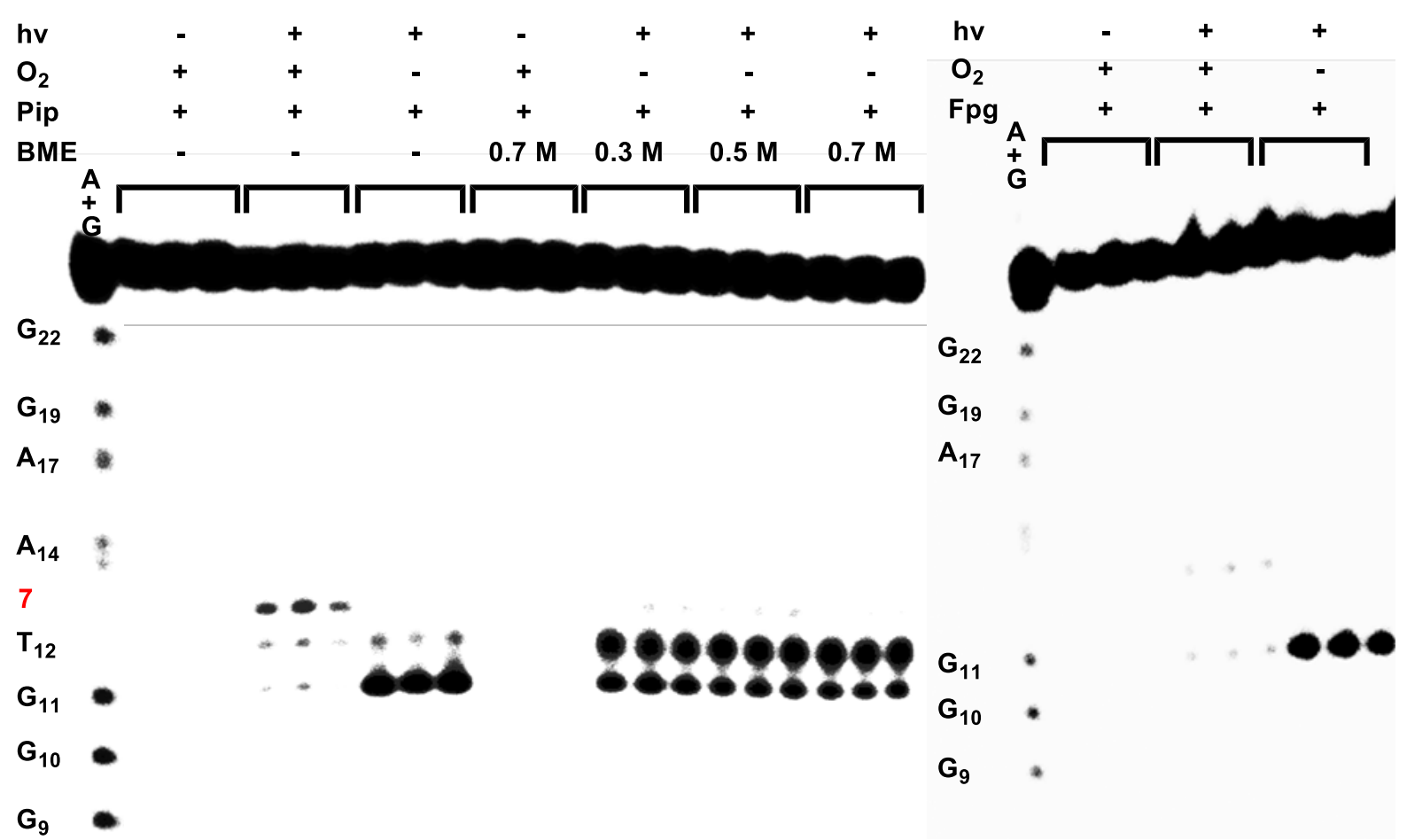

Figure S12. Photolysis of 5, ${ }^{32} \mathrm{P}-15$. A. Quantitative analysis B. Piperidine cleavage C. Fpg cleavage 
5'-32P-GTC GCA ACG G $_{10} \mathrm{G}_{11} \mathrm{~T}_{12}$ XAT CAC GTC GCT G-3'

3'- CAG CGT TGC C C A GTA GTG CAG CGA C-5'

\begin{tabular}{cccc}
\hline \multirow{2}{*}{ A. Sequence } & Conditions & \multicolumn{2}{c}{ \% cleavage } \\
\cline { 3 - 4 } & & $\mathrm{dG}_{11}$ & $\mathrm{dT}_{12}$ \\
\hline $5^{\prime}-\mathrm{G}_{9} \mathrm{G}_{10} \mathrm{G}_{11} \mathrm{~T}_{12} \mathrm{X}-3^{\prime}$ & Pip $(1 \mathrm{M})$ & $16.5 \pm 1.1$ & $4.7 \pm 0.6$ \\
$(\mathrm{X}=\mathbf{6 a})$ & $\mathrm{NaBH}_{4}(0.1 \mathrm{M})+\operatorname{Pip}(1 \mathrm{M})$ & $13.1 \pm 2.1$ & $1.6 \pm 0.3$ \\
\hline
\end{tabular}

B.
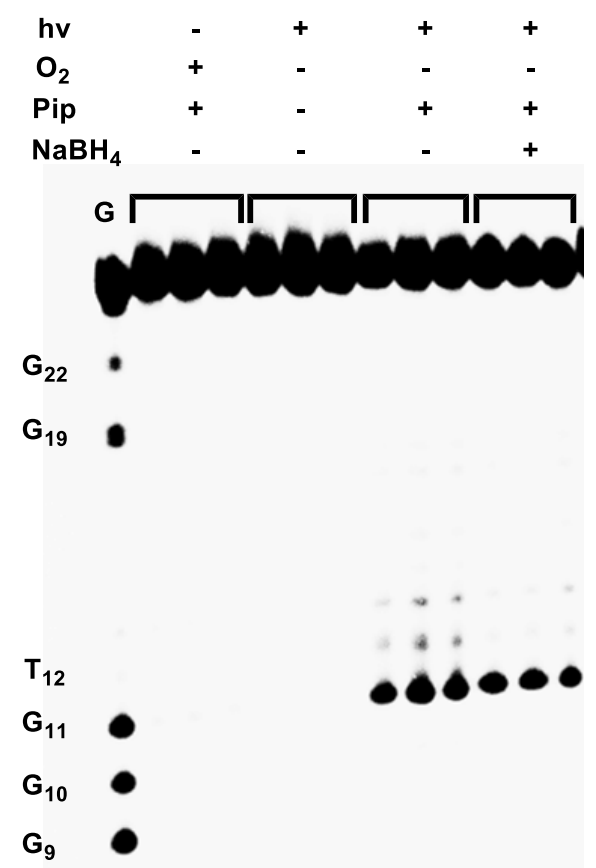

Figure S13. Photolysis of $5{ }^{\prime}-{ }^{32} \mathrm{P}-15$, followed by $\mathrm{NaBH}_{4} / \mathrm{Pip}$ treatments. A. Quantitative analysis B. Sample autoradiogram. 
5'-32P-GCA GCG TTG CCC $A_{13} T_{14} X$ AGT GCA GGC G-3' 3'-CGT CGC AAC GGG T A G TCA CGT CCG C-5'

\begin{tabular}{cccc}
\hline A. & & $\mathrm{dA}_{13}$ & $\mathrm{dT}_{14}$ \\
\cline { 3 - 4 }${ }^{\prime}-\mathrm{C}_{11} \mathrm{C}_{12} \mathrm{~A}_{13} \mathrm{~T}_{14} \mathrm{X}-3^{\prime}$ & $\operatorname{Pip}(1 \mathrm{M})$ & $1.9 \pm 0.1$ & $3.1 \pm 0.2$ \\
$(\mathrm{X}=\mathbf{6 a})$ & Fpg & $4.6 \pm 0.1$ & $0.4 \pm 0.2$ \\
\hline
\end{tabular}

B.

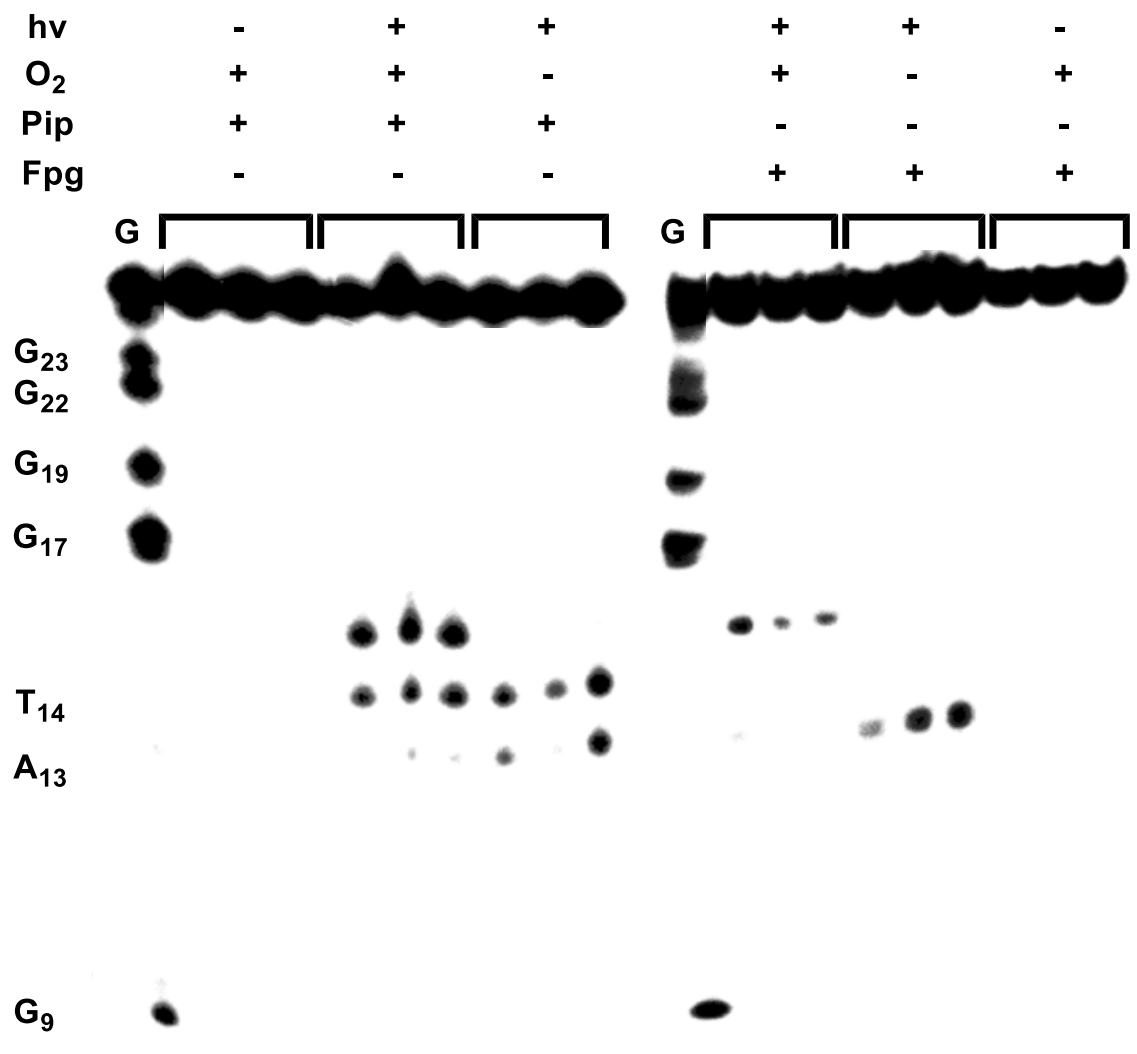

Figure S14. Photolysis of 5 ${ }^{3}{ }^{32} \mathrm{P}-18$. A. Quantitative analysis B. Sample autoradiogram. 
5'-GTC GCA ACX $\mathrm{T}_{10} \mathrm{G}_{11} \mathrm{G}_{12} \mathrm{G}_{13}$ AT CAC GTC GCT A- ${ }^{32} \mathrm{P}-\mathbf{3}^{\prime}$

3'-CAG CGT TGG A C C C TA GTG CAG CGA T-5'

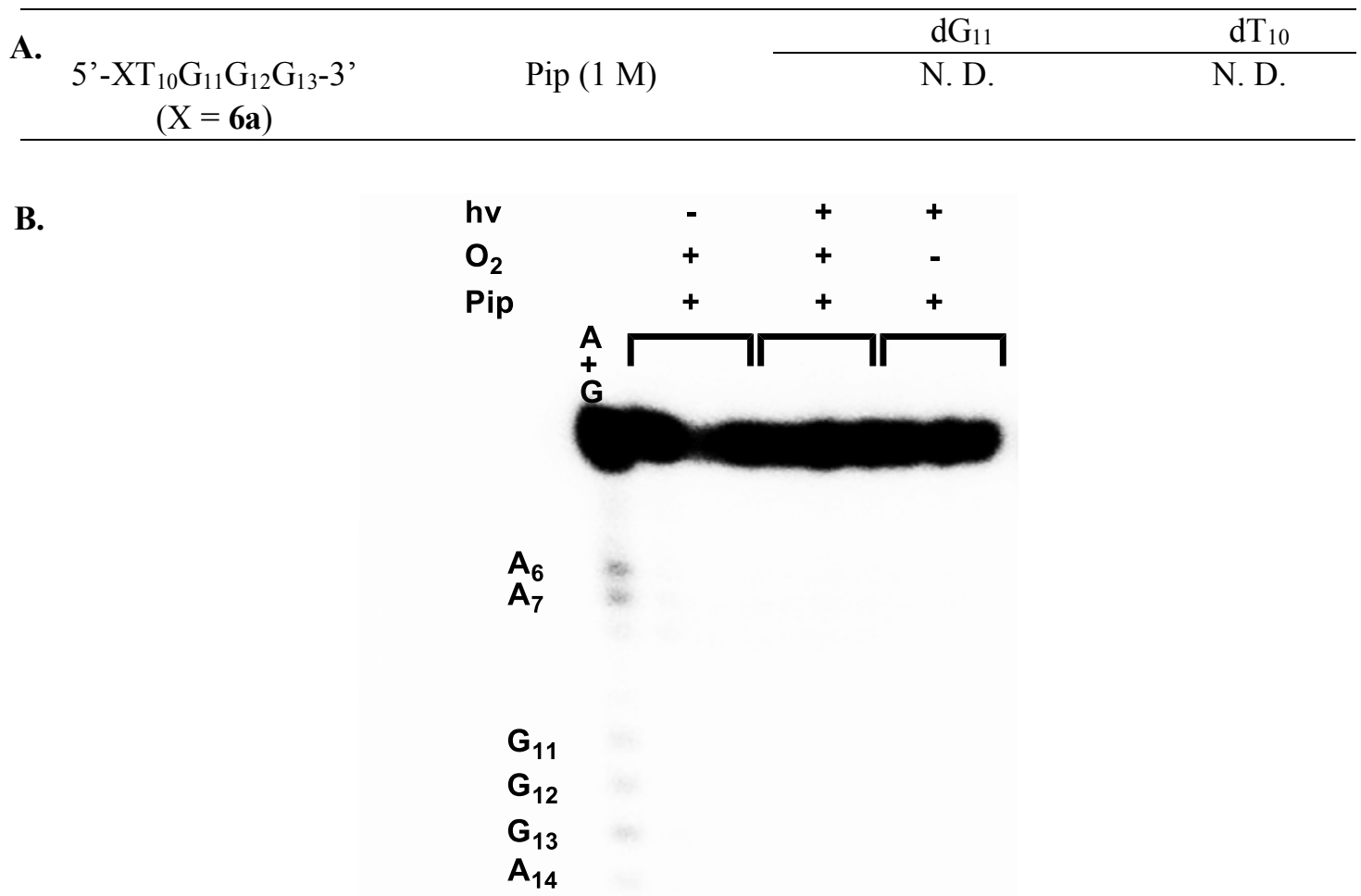

Figure S15. Photolysis of 3 ${ }^{3}{ }^{32} \mathrm{P}-17$. A. Quantitative analysis B. Sample autoradiogram. 
5'-32P-GTC GCA ACG G $_{10} G_{11} U_{12}$ XAT CAC GTC GCT G-3' 3'- CAG CGT TGC C C A GTA GTG CAG CGA C-5'

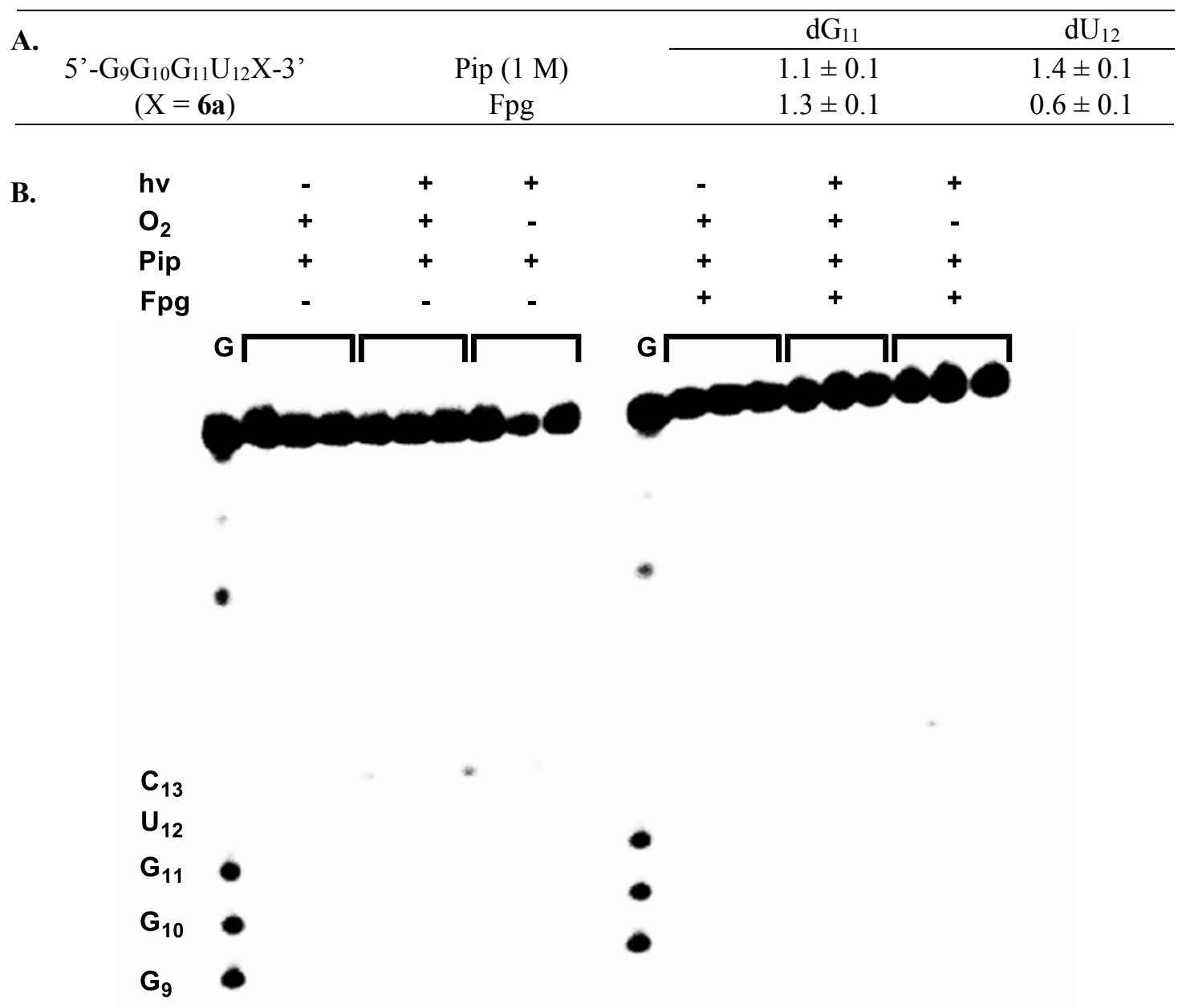

Figure S16. Photolysis of 5 ${ }^{3}{ }^{32} \mathrm{P}-16$. A. Quantitative analysis B. Sample autoradiogram. 


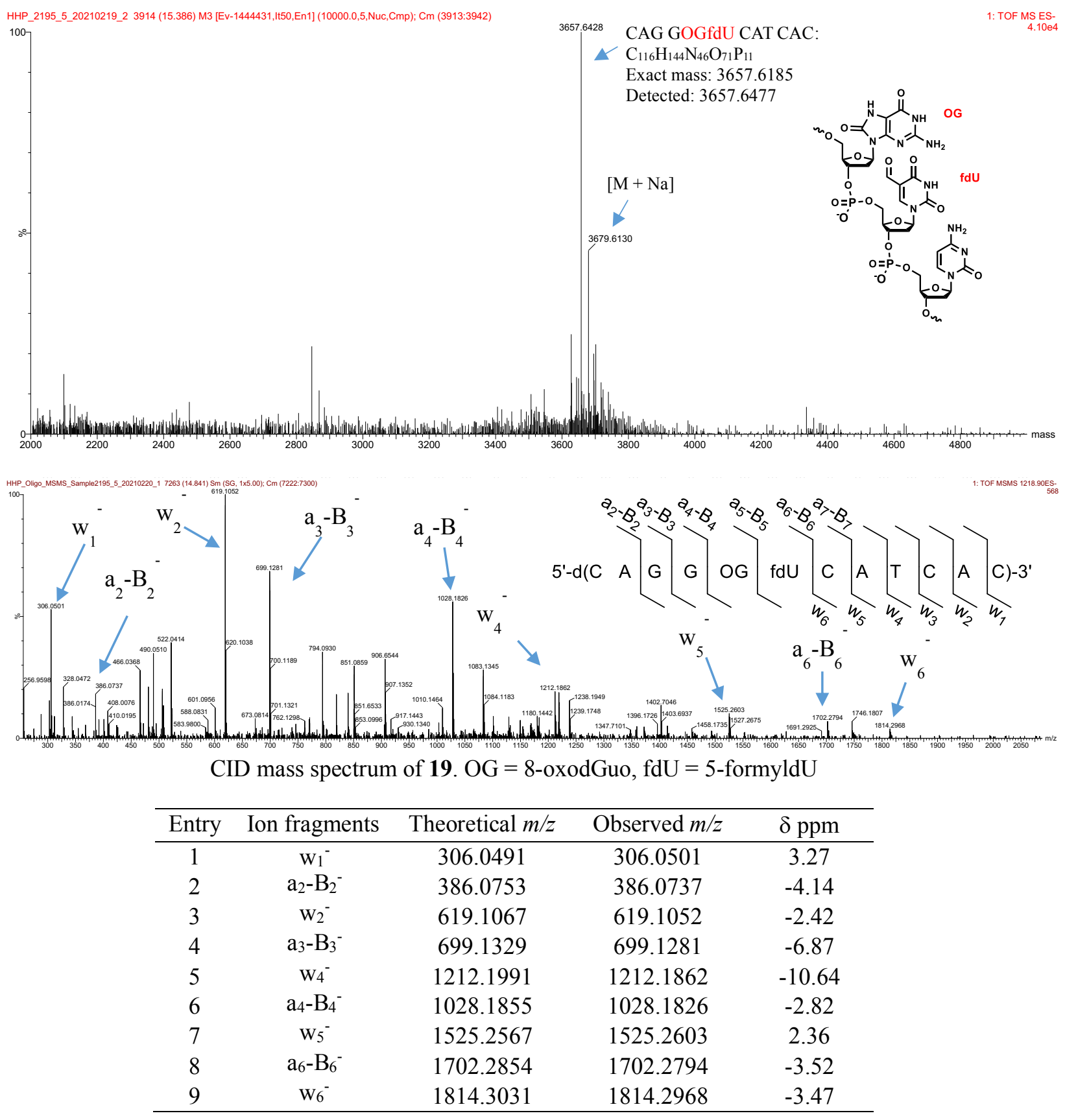

Figure S17. Mass spectral characterization of 19. 


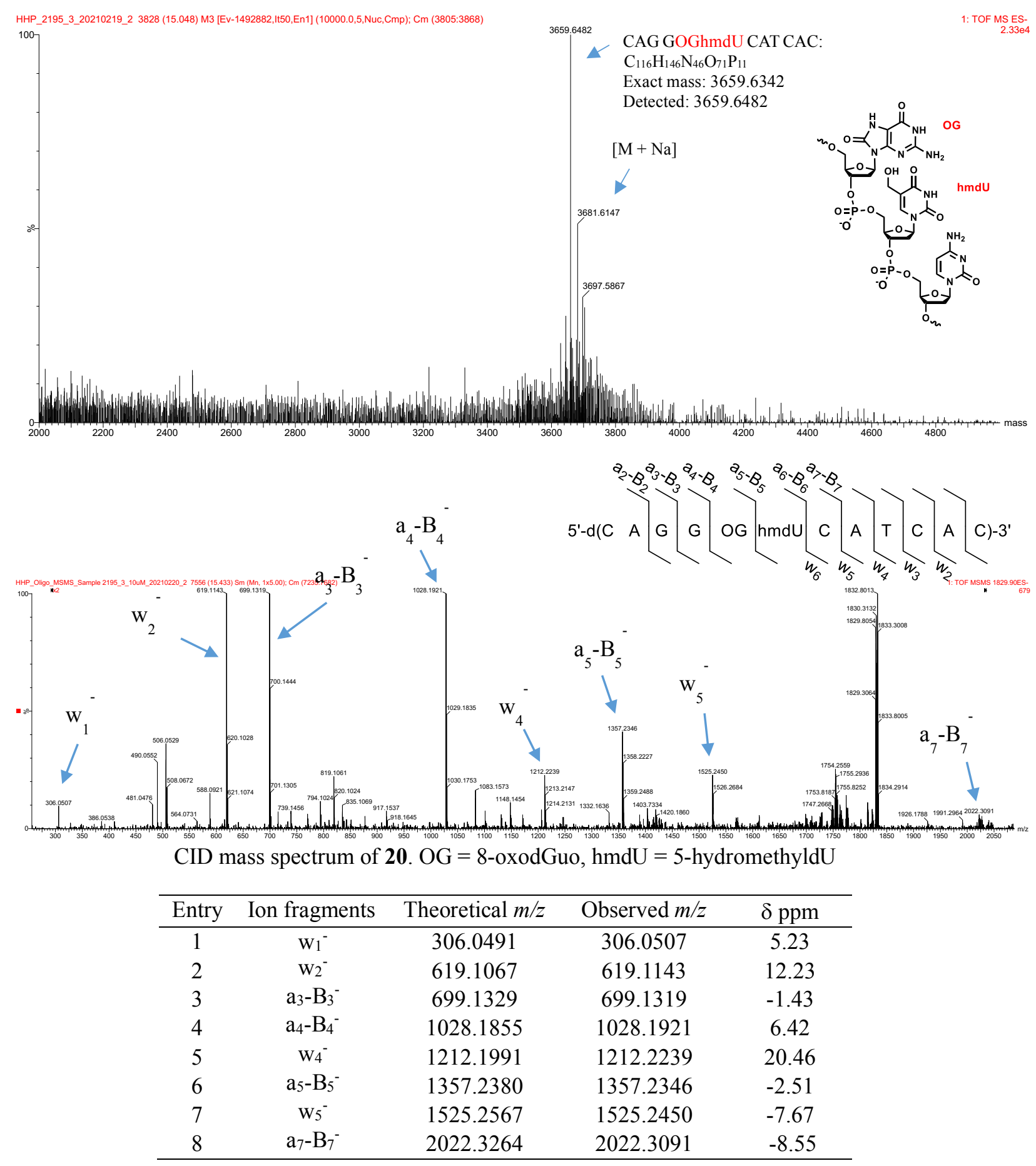

Figure S18. Mass spectral characterization of 20. 

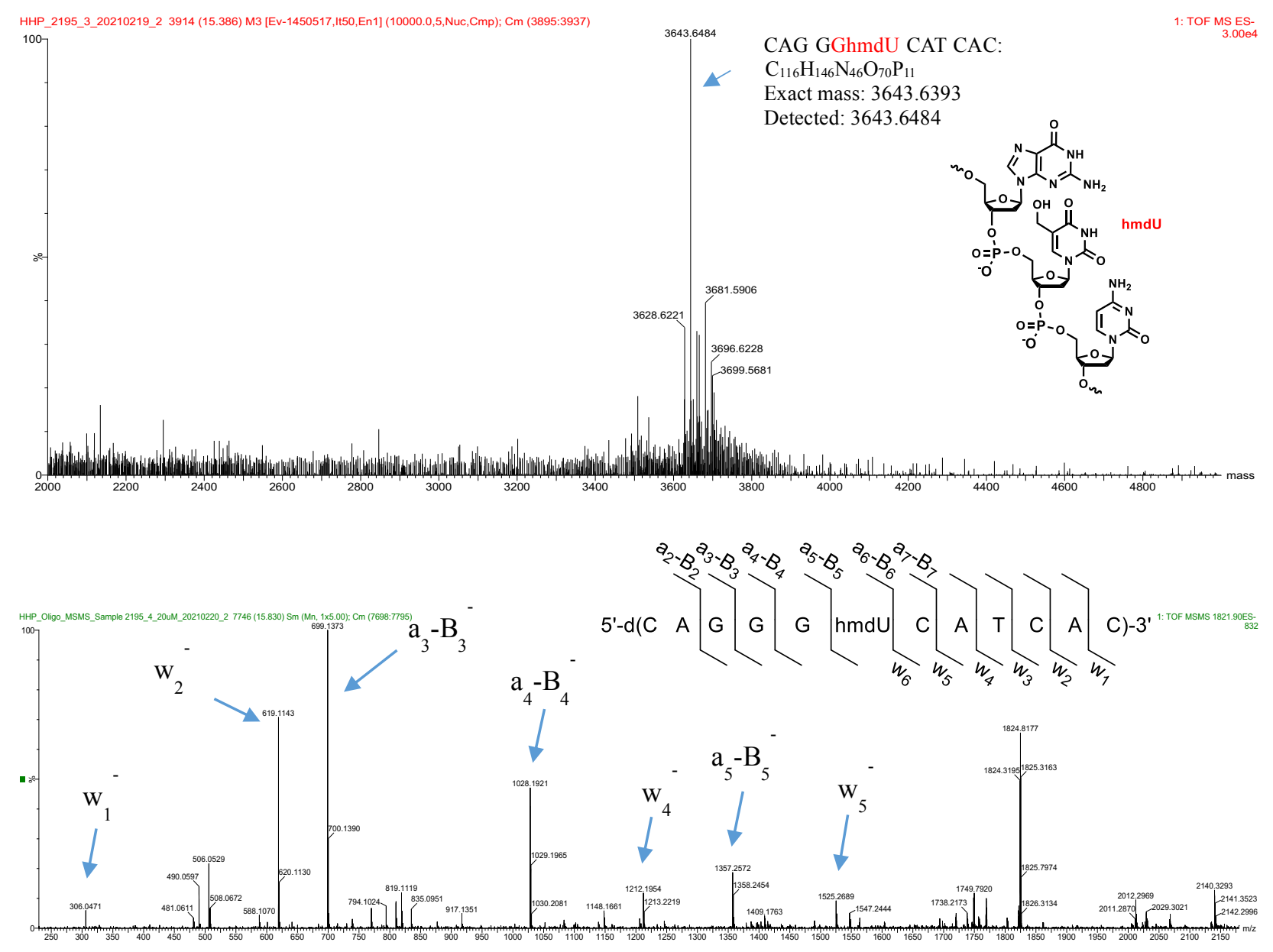

CID mass spectrum of the ion of $\mathbf{2 1} . \mathrm{hmdU}=5$-hydromethyldU

\begin{tabular}{ccccc}
\hline Entry & Ion fragments & Theoretical $m / z$ & Observed $m / z$ & $\delta \mathrm{ppm}$ \\
\hline 1 & $\mathrm{w}_{1}{ }^{-}$ & 306.0491 & 306.0471 & -6.53 \\
2 & $\mathrm{w}_{2}{ }^{-}$ & 619.1067 & 619.1143 & 12.28 \\
3 & $\mathrm{a}_{3}-\mathrm{B}_{3}{ }^{-}$ & 699.1329 & 699.1373 & 6.29 \\
4 & $\mathrm{a}_{4}-\mathrm{B}_{4}{ }^{-}$ & 1028.1855 & 1028.1921 & 6.42 \\
5 & $\mathrm{w}_{4}{ }^{-}$ & 1212.1991 & 1212.1954 & -3.05 \\
6 & $\mathrm{a}_{5}-\mathrm{B}_{5}{ }^{-}$ & 1357.2380 & 1357.2572 & 14.15 \\
7 & $\mathrm{w}_{5}{ }^{-}$ & 1525.2567 & 1525.2689 & 8.00 \\
\hline
\end{tabular}

Figure S19. Mass spectral characterization of 21. 


\section{5'-32P- CGC AAC $\mathrm{G}_{7} \mathrm{G}_{8} \mathrm{G}_{9} \mathrm{~T}_{10} \times$ C CAT ATG TAC-3' 3'- GCG TTG C C C A GG GTA TAC ATG-5'}

\begin{tabular}{cccc}
\hline A. $5{ }^{\prime}-\mathrm{G}_{7} \mathrm{G}_{8} \mathrm{G}_{9} \mathrm{~T}_{10} \mathrm{X}-3^{\prime}$, & & $\mathrm{dT}_{10}$ & $\mathrm{dG}_{9}$ \\
\cline { 3 - 4 }$(\mathrm{X}=\mathbf{6 a})$ & Pip (1 M) & $1.6 \pm 0.1$ & $11.0 \pm 0.5$ \\
& Fpg & $0.4 \pm 0.1$ & $8.3 \pm 1.9$ \\
\hline
\end{tabular}

B.

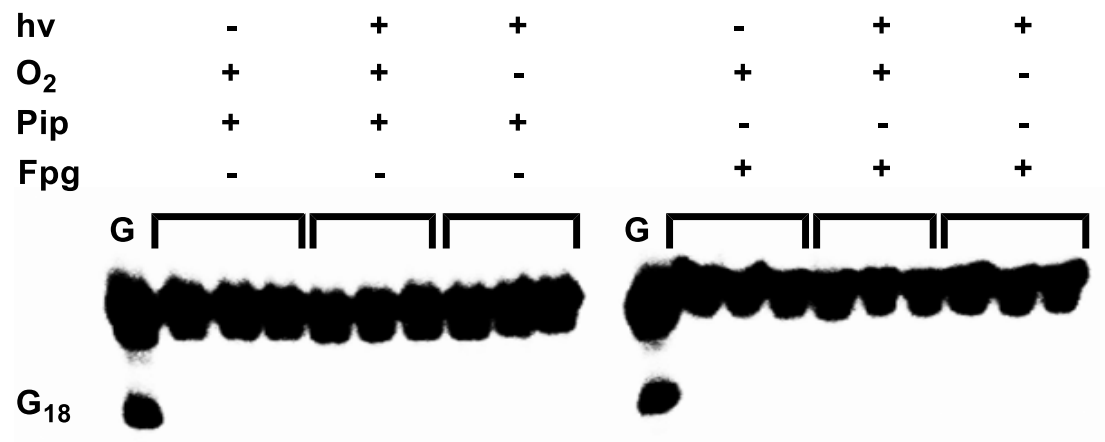

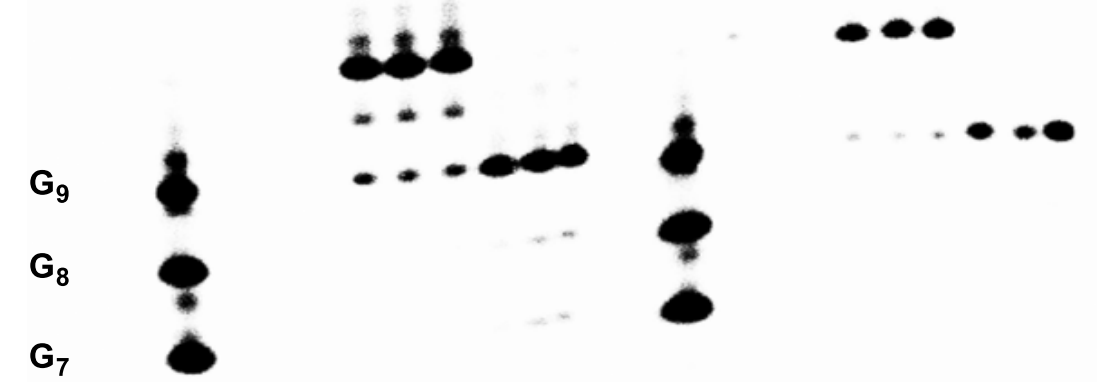

Figure S20. Photolysis of $5^{\prime}-{ }^{32} \mathrm{P}-22$ on the modified strand. A. Quantitative analysis B. Sample autoradiogram 


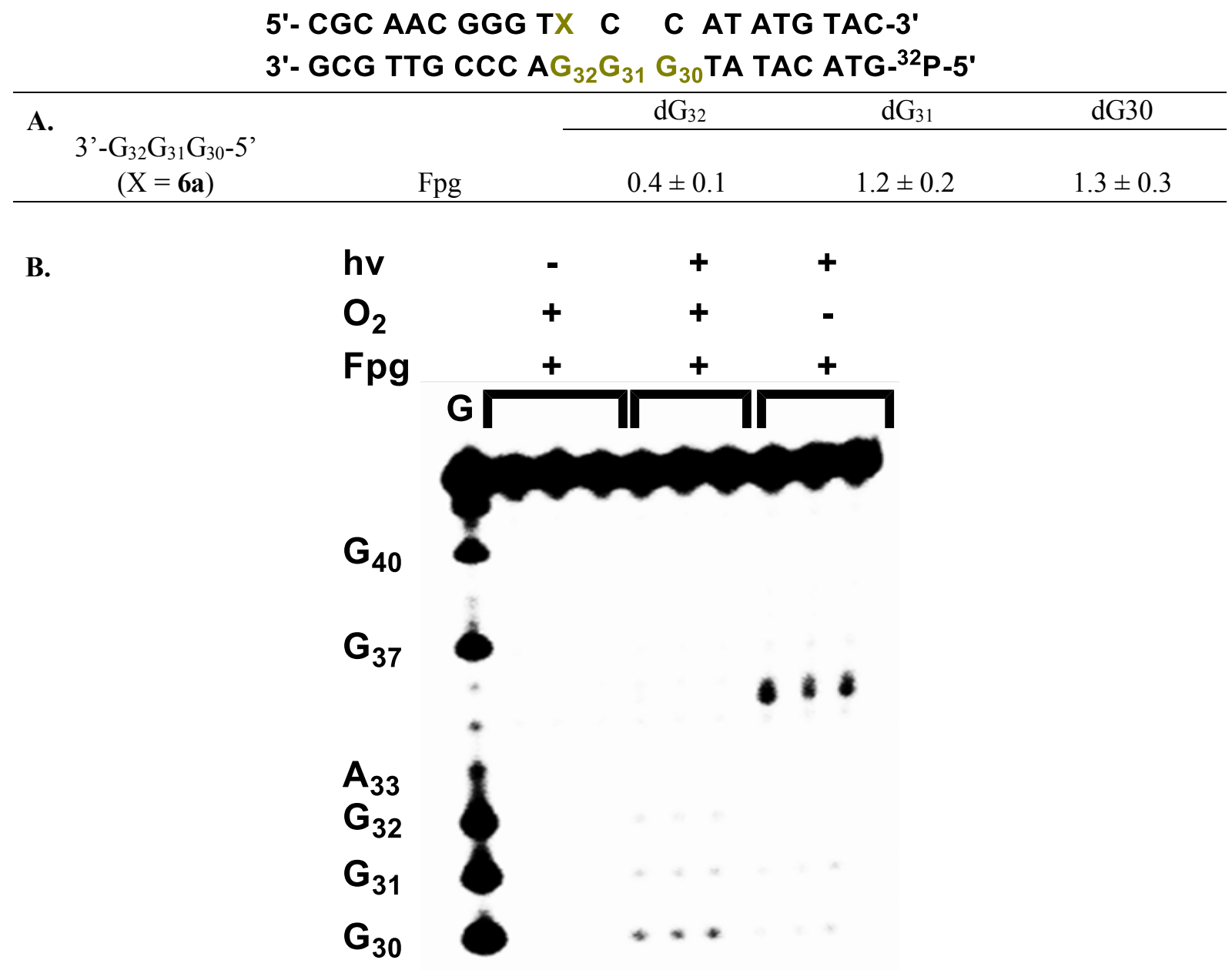

Figure S21. Photolysis of $5{ }^{3}{ }^{32} \mathrm{P}-22$ labeled on the opposite strand. A. Quantitative analysis B. Sample autoradiogram 


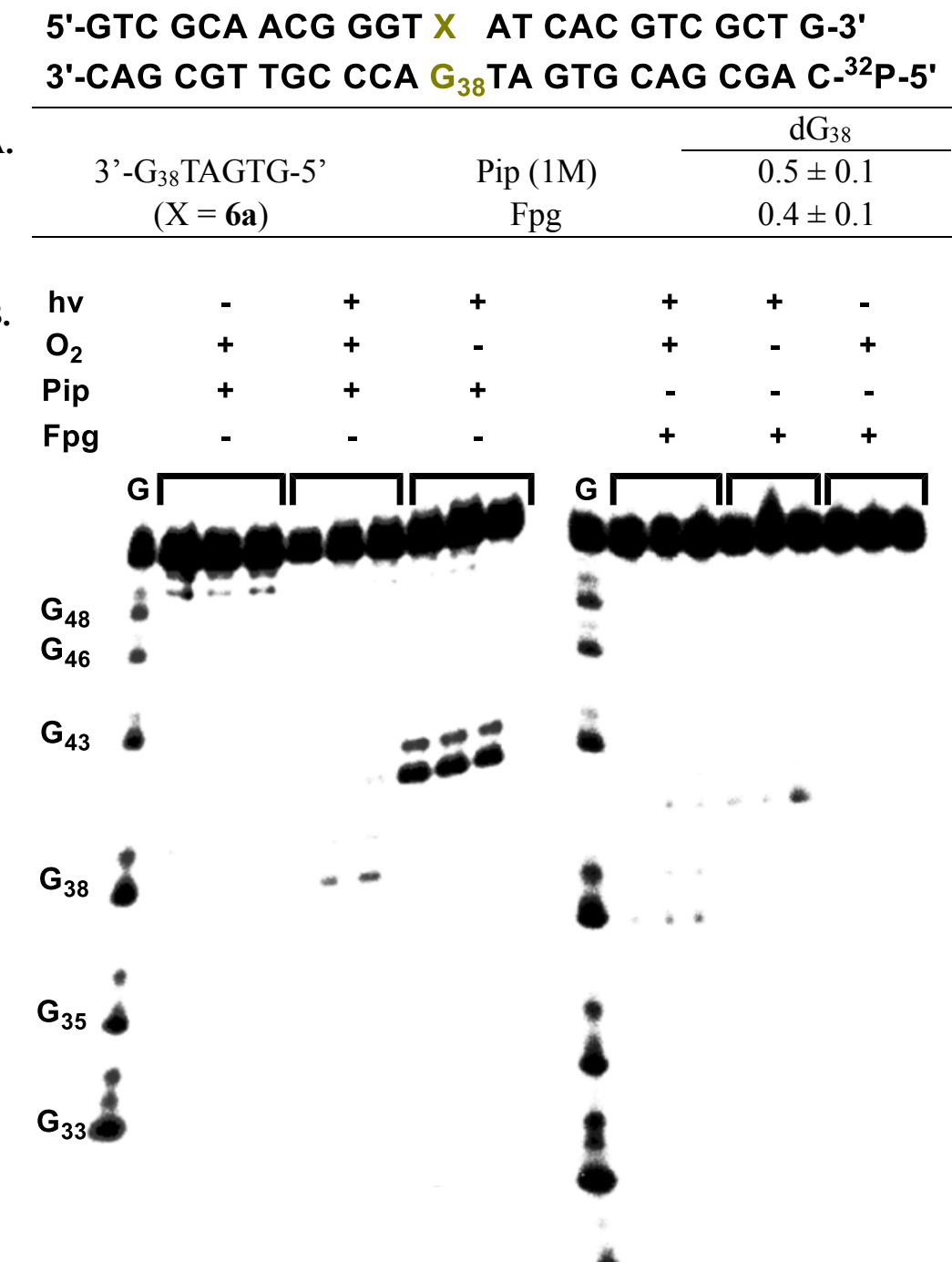

Figure S22. Photolysis of $5^{{ }^{3}-}{ }^{32} \mathrm{P}-15$ labeled on the opposite strand. A. Quantitative analysis B. Sample autoradiogram. 


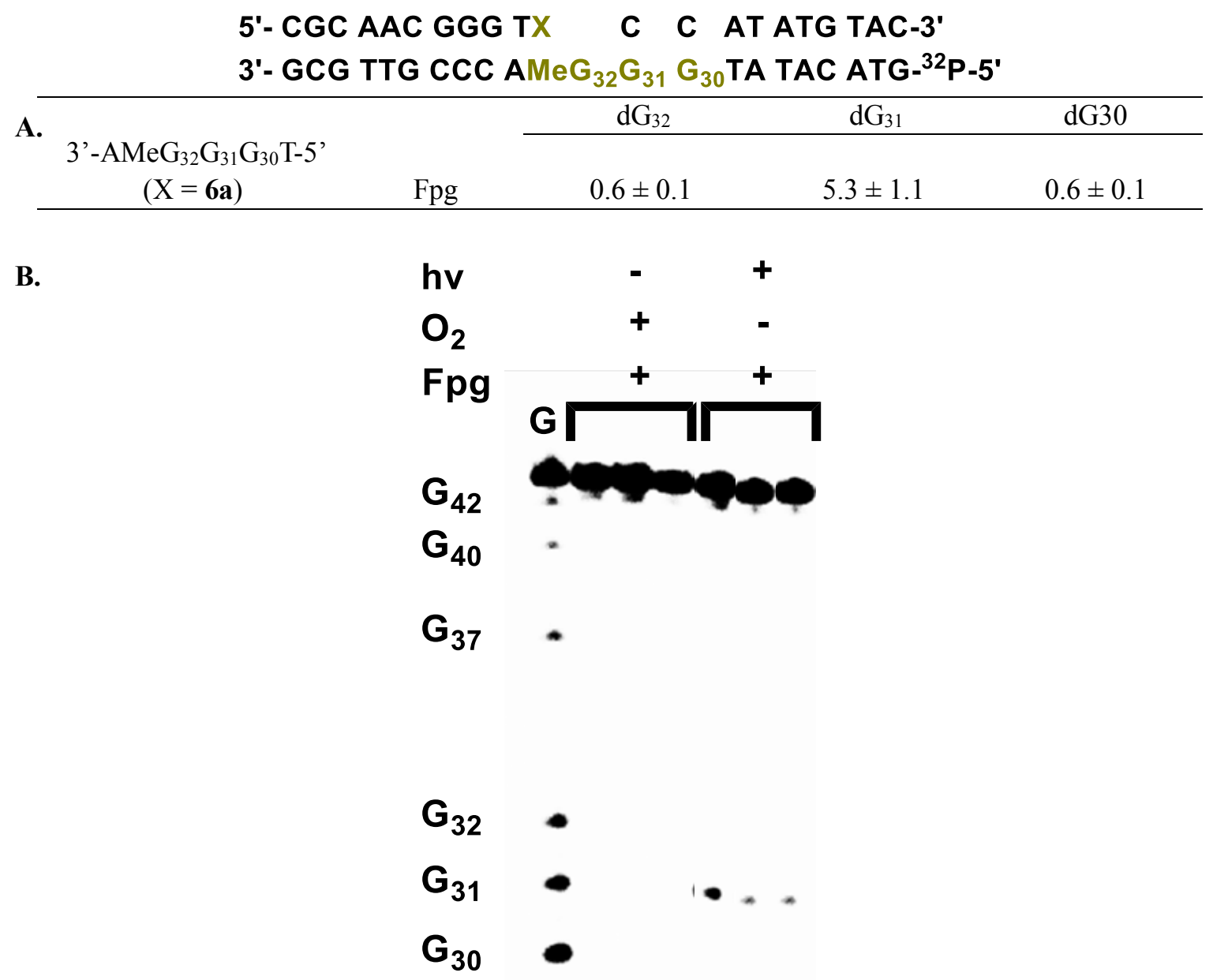

Figure S23. Photolysis of $5{ }^{3}{ }^{32} \mathrm{P}-23$ labeled on the opposite strand. A. Quantitative analysis B. Sample autoradiogram 
5'- CGC AAC GGG TC C C AT ATG TAC-3'

3'- GCG TTG C CC AG ${ }_{32} \mathrm{G}_{31} \mathrm{G}_{30}$ TA TAC ATG- ${ }^{32}$ P-5'

\begin{tabular}{lccl}
\hline A. $3{ }^{\prime}-\mathrm{G}_{32} \mathrm{G}_{31} \mathrm{G}_{30} \mathrm{~T}_{29}-5$ & & $\mathrm{dT}_{10}$ & $\mathrm{dG}_{9}$ \\
\cline { 3 - 4 } & Pip $(1 \mathrm{M})$ & N. D. & N.D. \\
& Fpg & N.D. & N.D. \\
\hline
\end{tabular}

B.
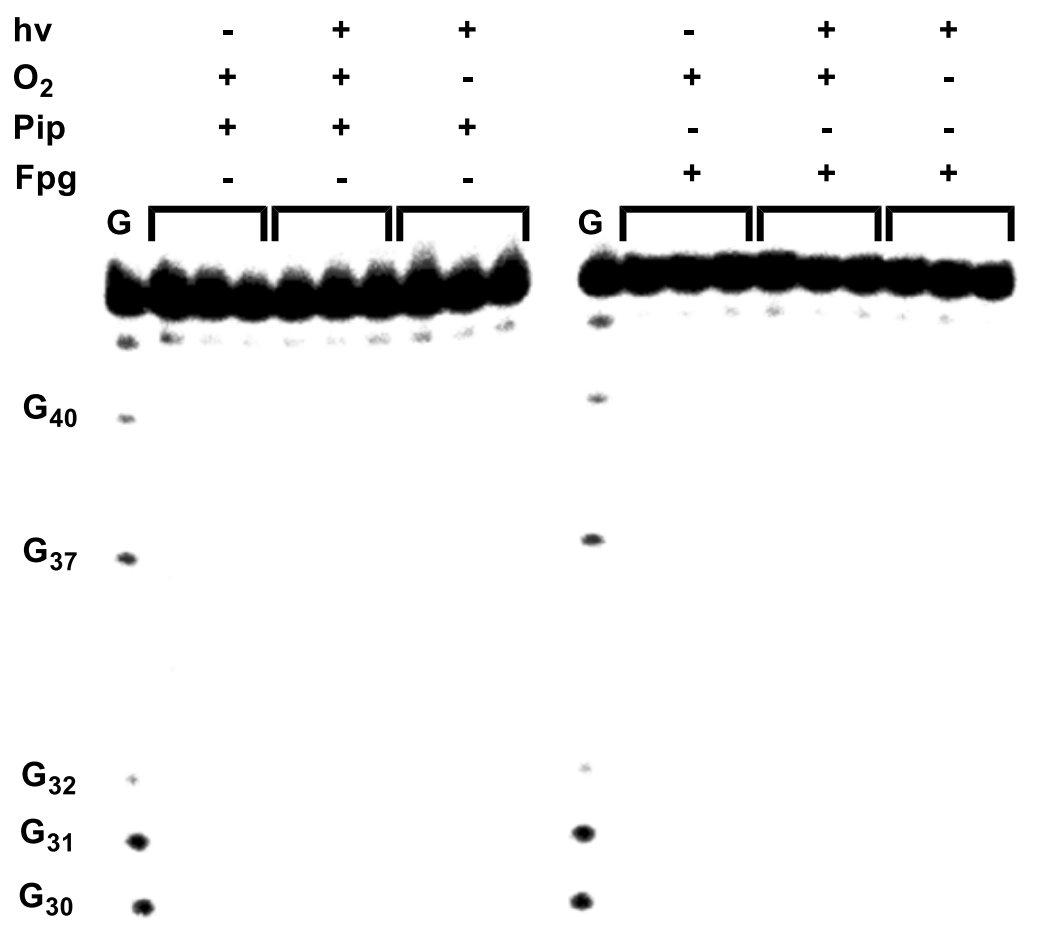

Figure S24. Photolysis of $5{ }^{3}-{ }^{32} \mathrm{P}-15$ labeled on the GGG containing strand. A. Quantitative analysis B. Sample autoradiogram. 
5'- GTC GCA ACG GG $11 T_{12} \quad X \quad A \quad T$ CAC GTC GCT G-3'

3'- CAG CGT TGC C C A $\mathrm{MeG}_{38} \mathrm{~T}_{37} \mathrm{~A}_{36}$ GTG CAG CGA C-32 P-5'

\begin{tabular}{llccc}
\hline A. & & $\mathrm{dG}_{38}$ & $\mathrm{~T}_{37}$ & $\mathrm{dA}_{36}$ \\
\cline { 3 - 5 }$-\mathrm{MeG}_{38} \mathrm{~T}_{37} \mathrm{~A}_{36}{ }^{-5}$, & $\operatorname{Pip}(1 \mathrm{M})$ & $0.9 \pm 0.1$ & $2.3 \pm 0.5$ & $0.8 \pm 0.1$
\end{tabular}

B.

$\begin{array}{lllll}\text { hv } & - & + & + \\ \mathrm{O}_{2} & + & + & - \\ \mathrm{Pip} & \mathrm{G} & + & + & + \\ & & & & \end{array}$

$\mathbf{G}_{48}$

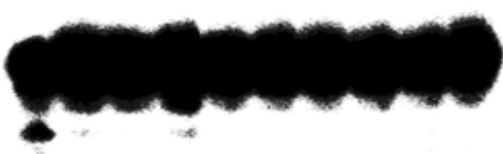

$\mathbf{G}_{46}$

$\mathbf{G}_{43}$

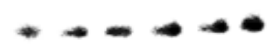

$\mathbf{G}_{38}$

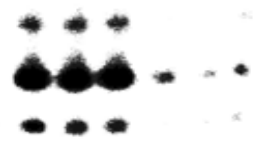

$\mathbf{G}_{35}$

$\mathbf{G}_{33}$

Figure S25. Photolysis of $5{ }^{3}{ }^{32} \mathrm{P}-27$ labeled on the opposite strand. A. Quantitative analysis B. Sample autoradiogram. 
5'-32P-GTC GCA ACG 9 G $_{10} \mathrm{G}_{11} \mathrm{~T}_{12} \quad$ X AT CAC GTC GCT G-3' 3'- CAG CGT TGC C C A MeGTA GTG CAG CGA C-5'

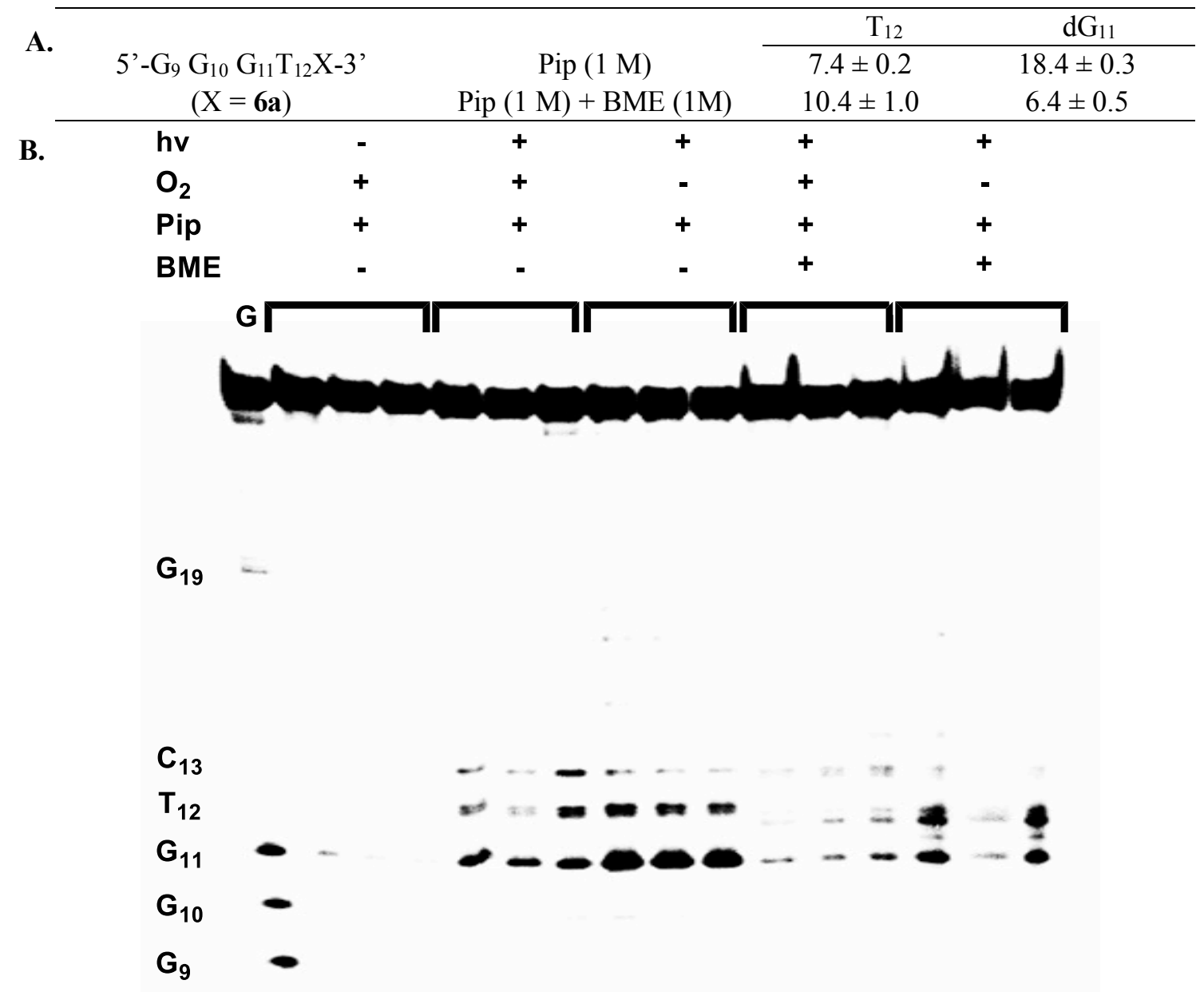

Figure S26. Photolysis of $5^{3}-{ }^{32} \mathrm{P}-27$ labeled on the modified strand. A. Quantitative analysis B. Sample autoradiogram. 
5'-CAG GGT XAT CAC-3', X = 6a

Calcd. $\mathrm{m} / \mathrm{z}: 3764.6556$

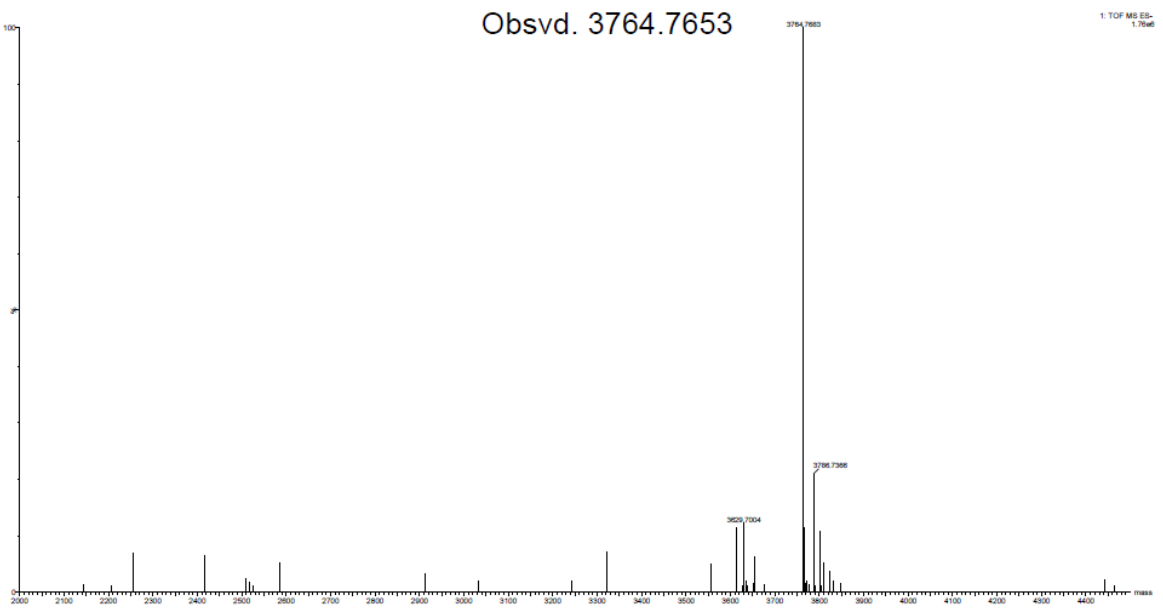

5'-GTC GCA ACG GGT XAT CAC GTC GCT G-3' $X=6 a$

Calcd. $m / z: 7797.0$

Obsvd. 7795.3

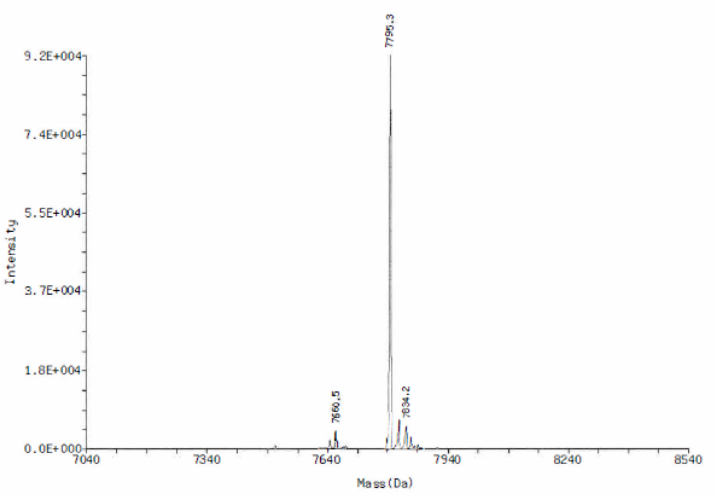


5'-GTC GCA ACG GGT XAT CAC GTC GCT G-3'

$$
X=6 a
$$

Calcd. $m / z: 7821$

Obsvd. 7820.1

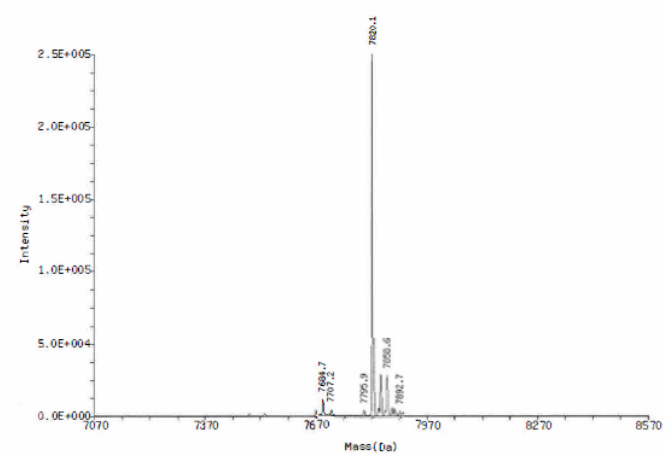

5'-GTC GCA ACX TGG GAT CAC GTC GCT-3'

$X=6 a$

Calcd. $m / z: 7468.7$

Obsvd. 7468.3

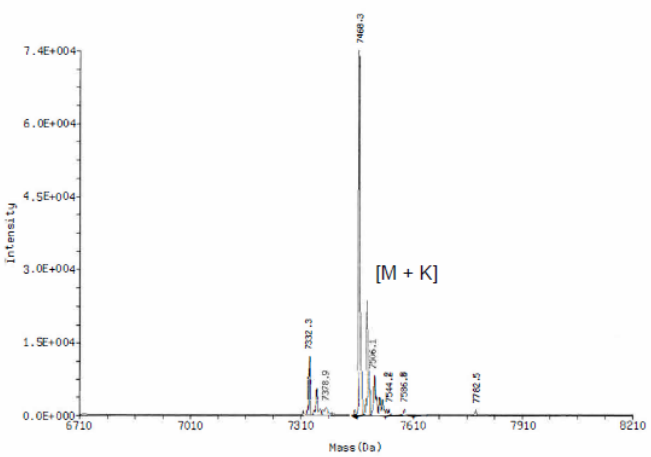


5'-CGC AAC GGG TXC CAT ATG TAC-3'

$X=6 a$

Calcd. $\mathrm{m} / \mathrm{z}: 6528.2$

Obsvd. 6528.0

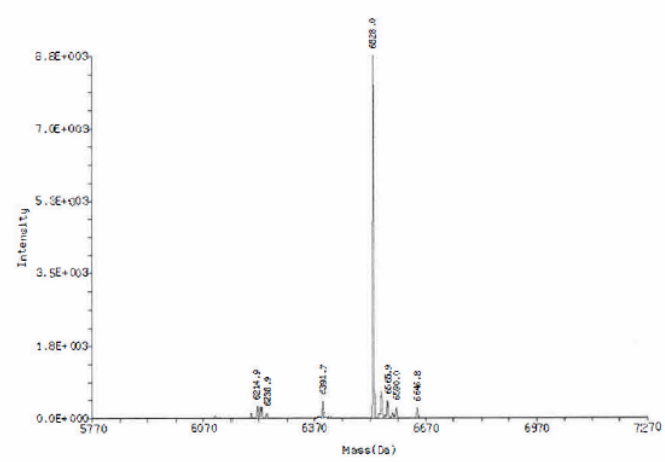

5'-GTC GCA ACG GGU XAT CAC GTC GCT G-3'

$$
X=6 a
$$

Calcd. $m / z: 7783.0$

Obsvd. 7783.5

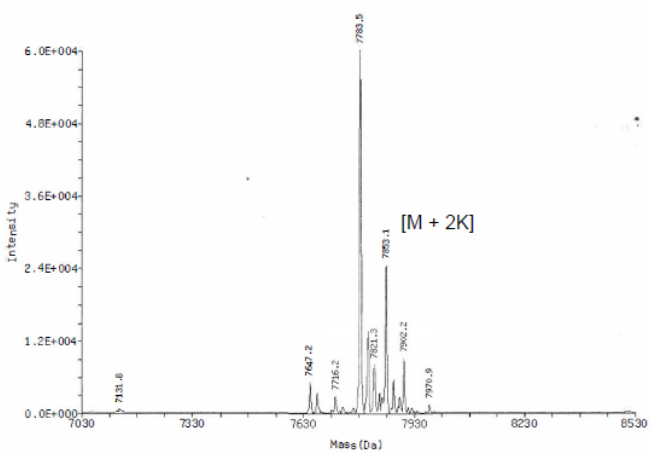


5'-GTA CAT ATG GXA CCC GTT GCG-3'

$X=06-M e-d G$

Calcd. $\mathrm{m} / \mathrm{z}$ : 6476.2

Obsvd. 6475.1

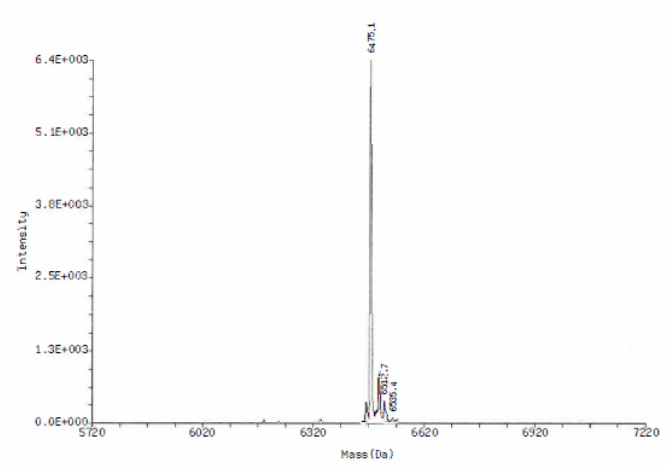

GTG ATX ACC CTG X = 06-Me-dG

Calcd. $m / z=3675.4$

Obsvd. 3674.5

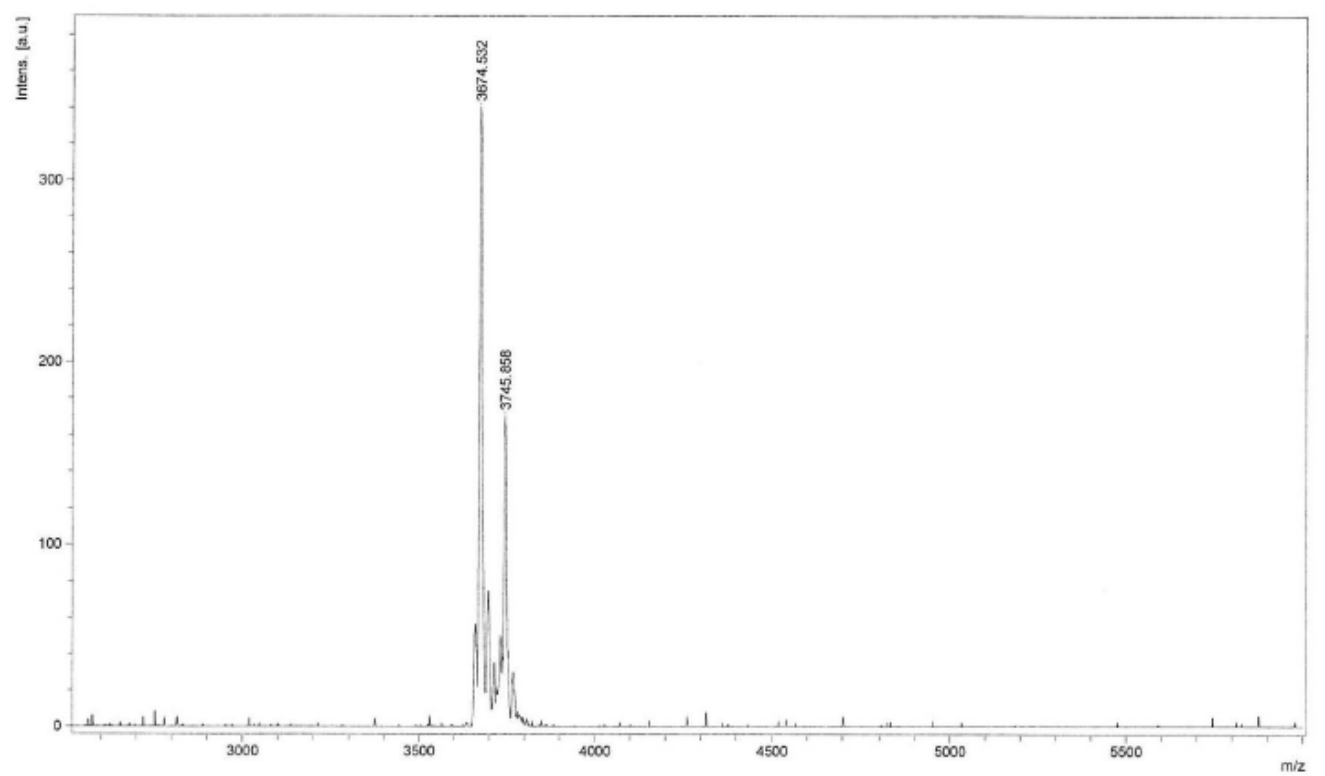




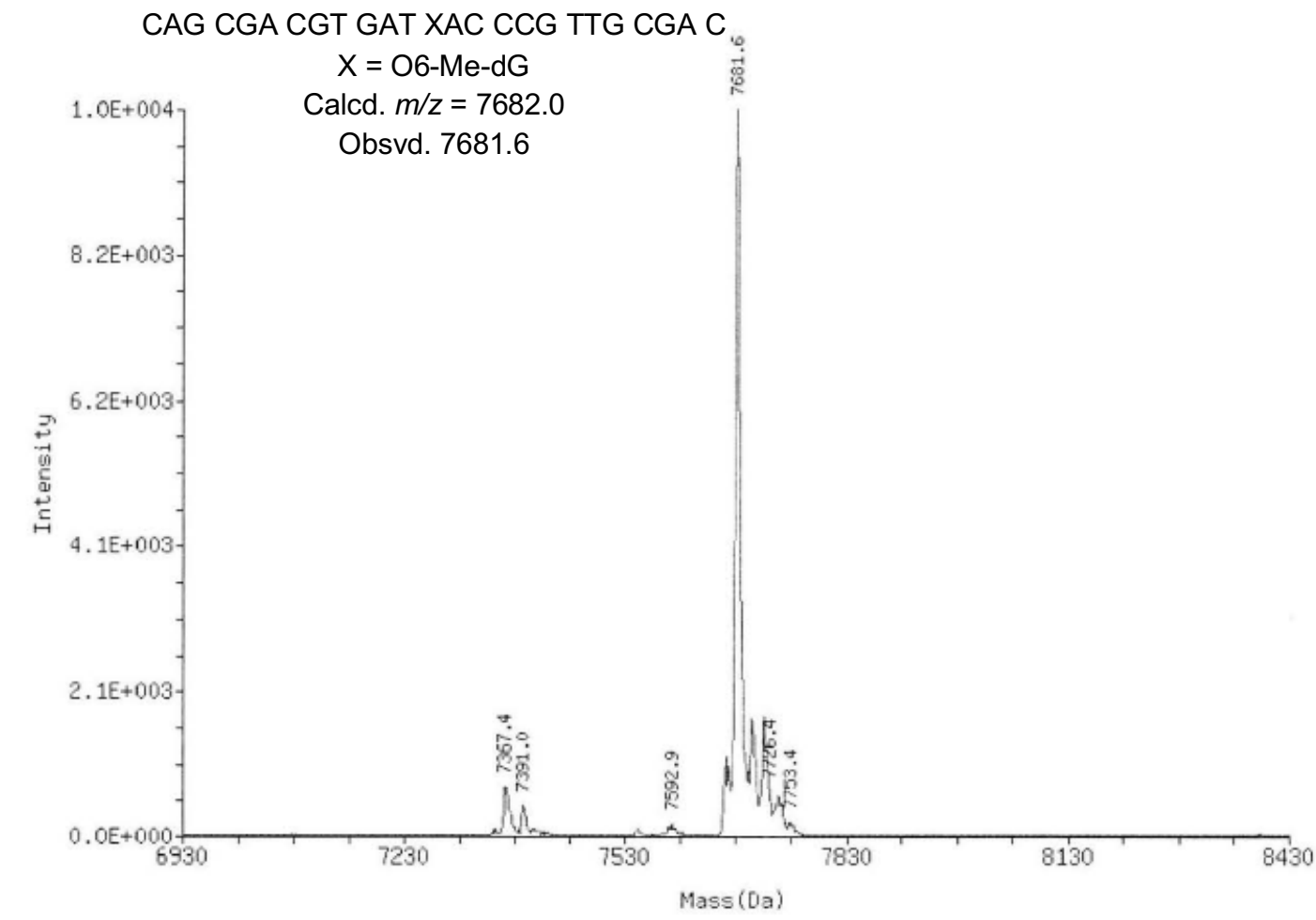

Figure S27. LC-MS and ESI-MS analysis of oligonucleotides containing 6a or O6-Me-dG.

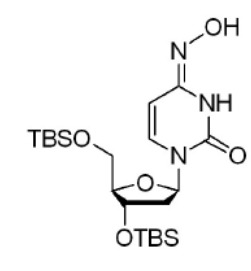

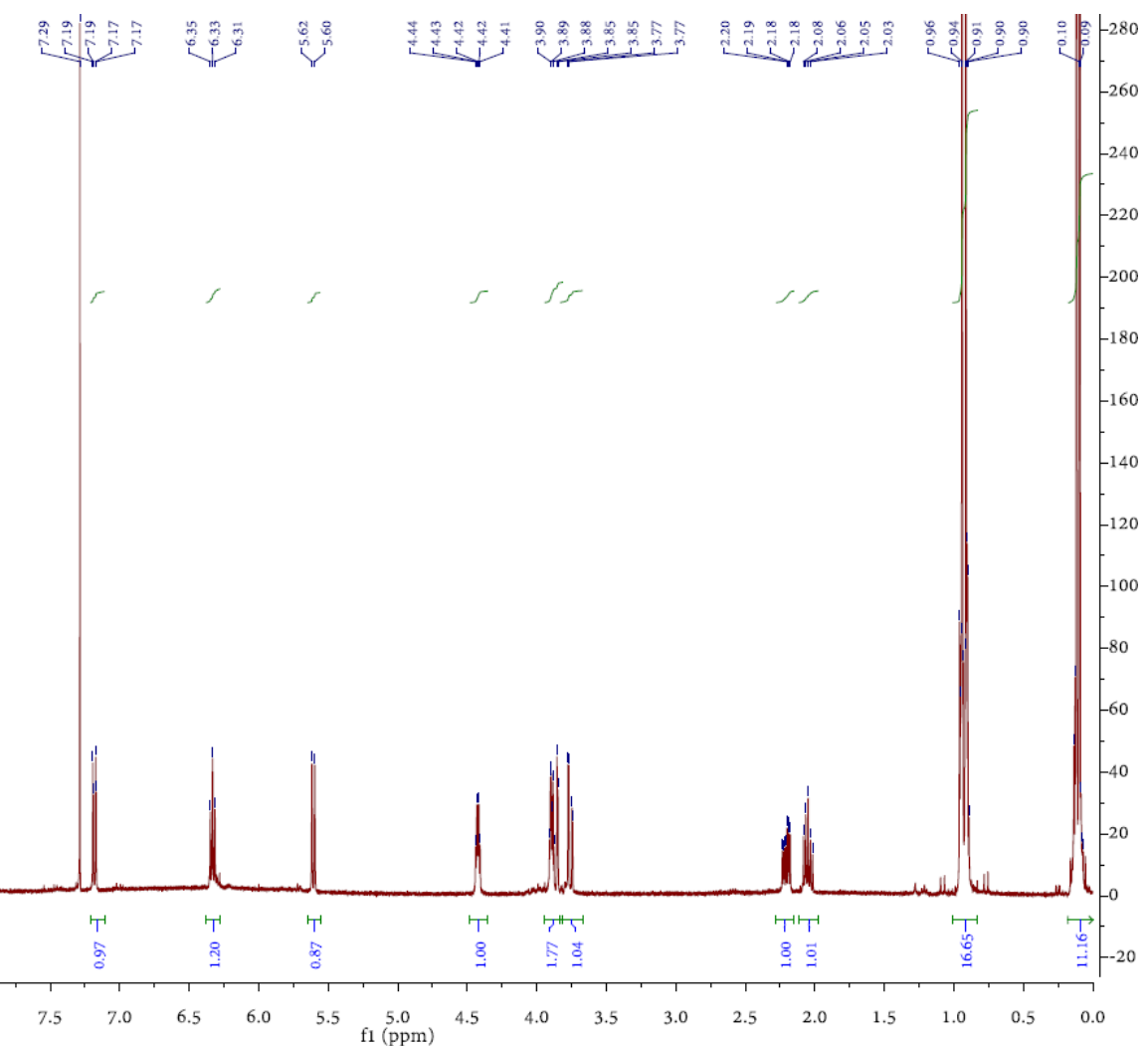

Figure S28. ${ }^{1} \mathrm{H}$ NMR of 4. 

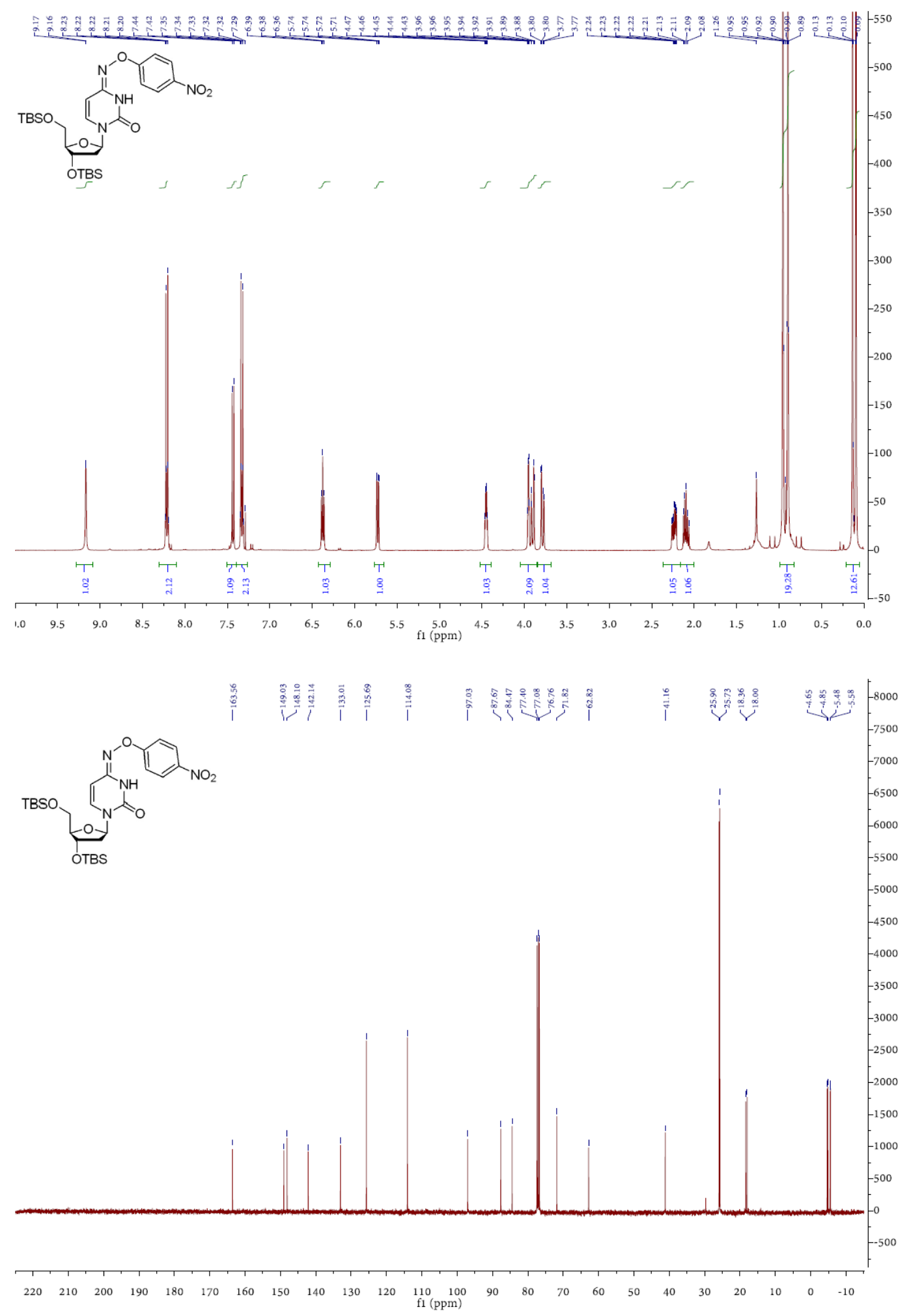

Figure S29. ${ }^{1} \mathrm{H}$ and ${ }^{13} \mathrm{C}$ NMR of $5 \mathbf{a}$. 

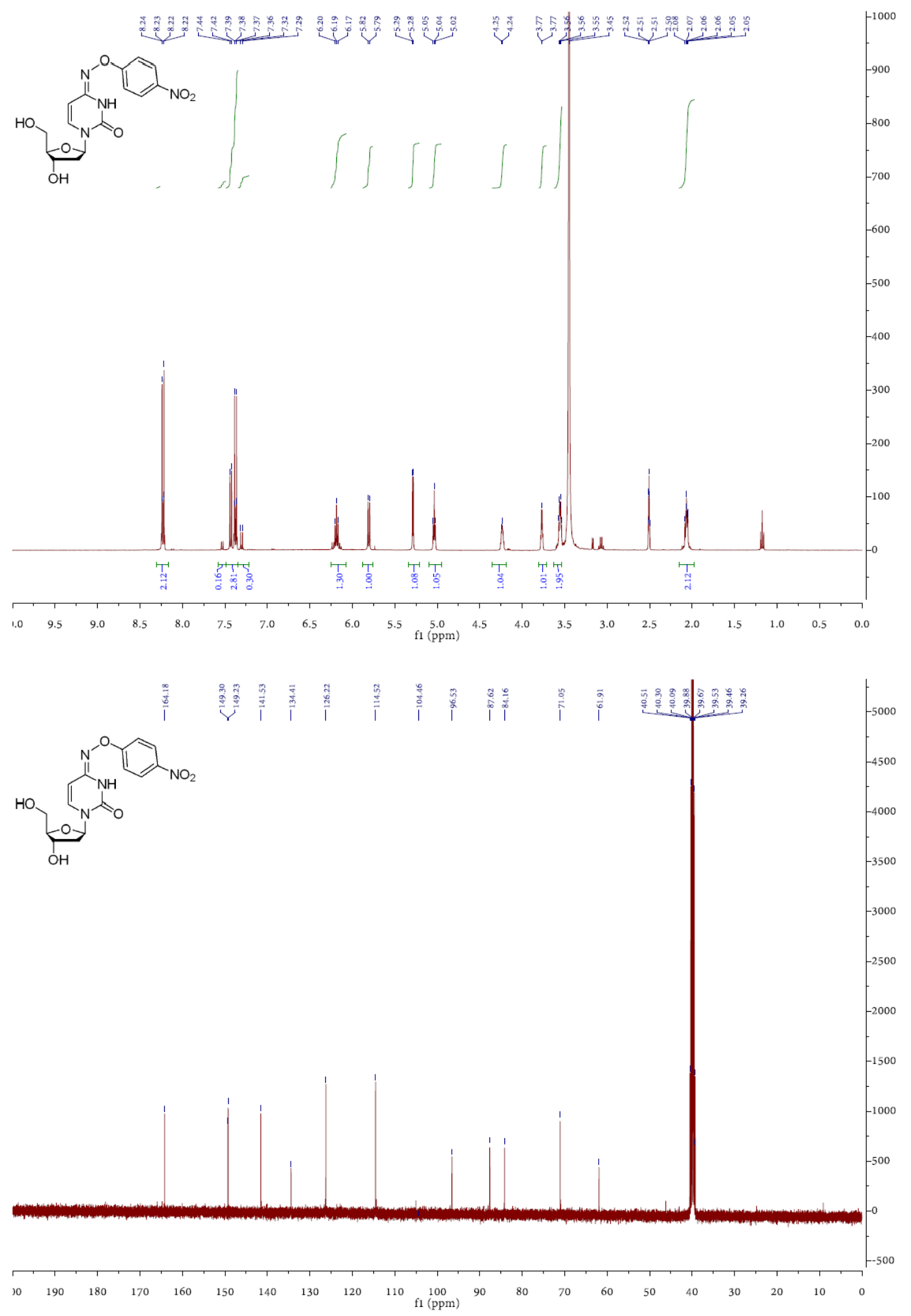

Figure S30. ${ }^{1} \mathrm{H}$ and ${ }^{13} \mathrm{C}$ NMR of $\mathbf{6 a}$. 

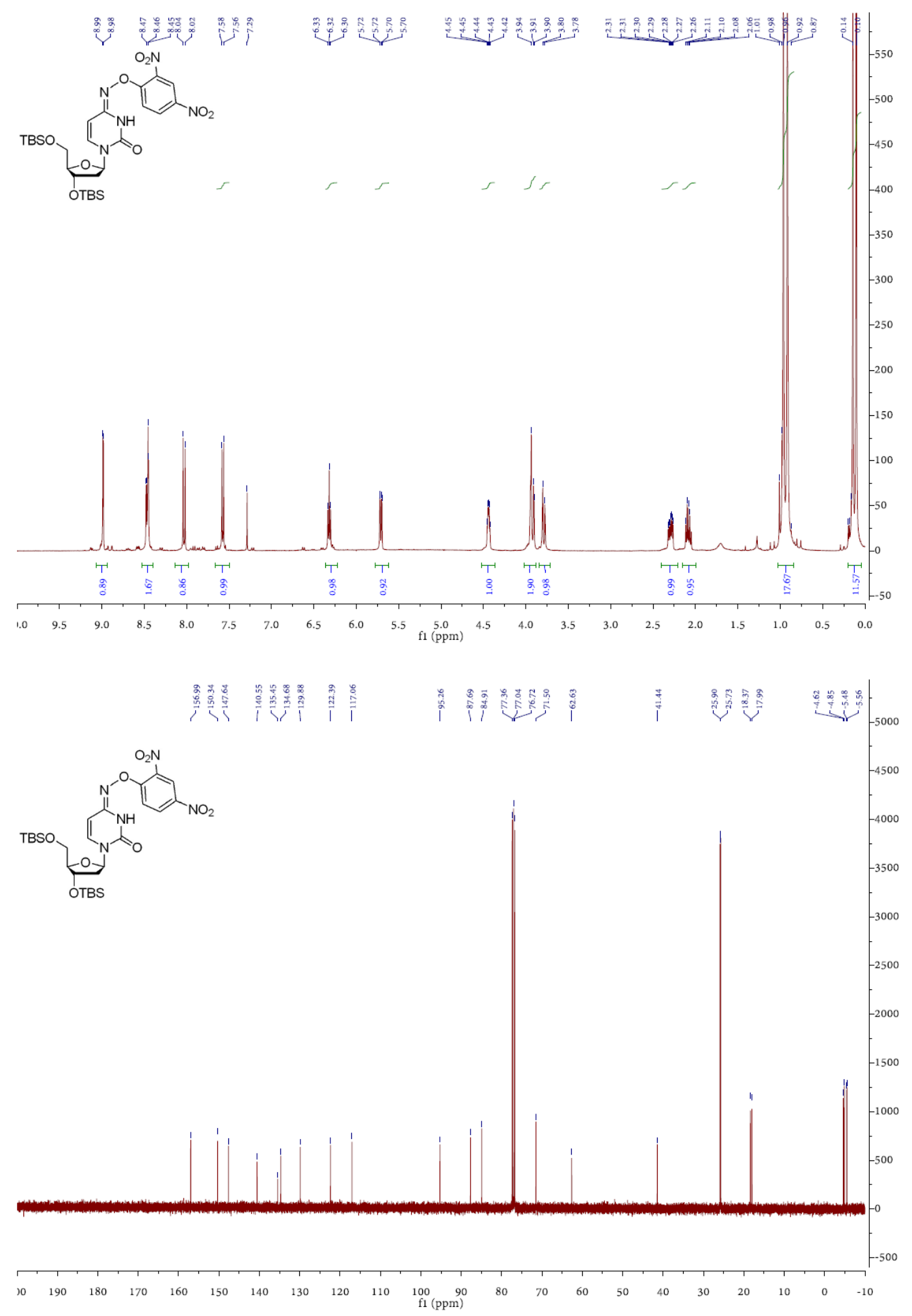

Figure S31. ${ }^{1} \mathrm{H}$ and ${ }^{13} \mathrm{C}$ NMR of $\mathbf{5 b}$. 

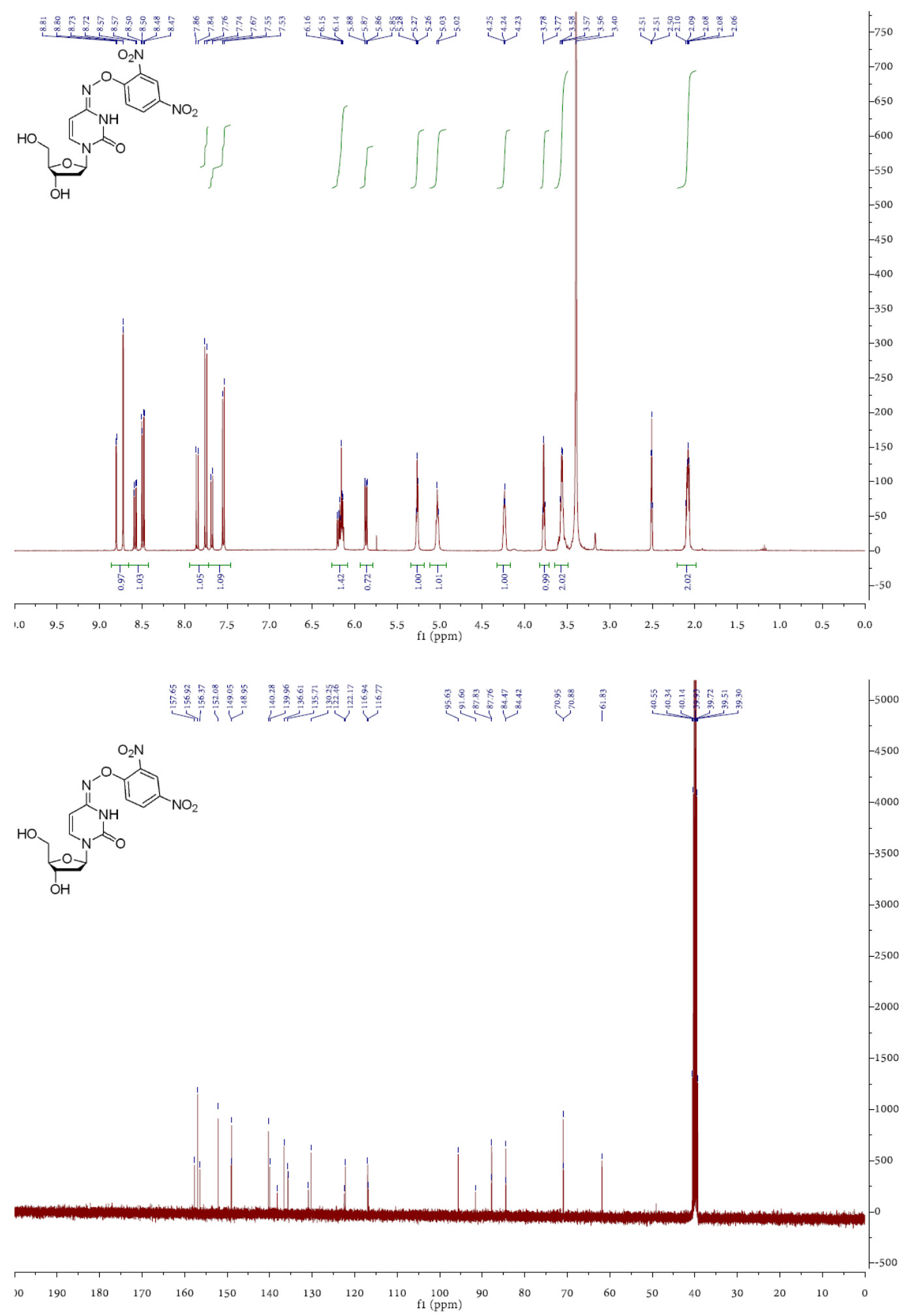

Figure S32. ${ }^{1} \mathrm{H}$ and ${ }^{13} \mathrm{C}$ NMR of $\mathbf{6 b}$. 

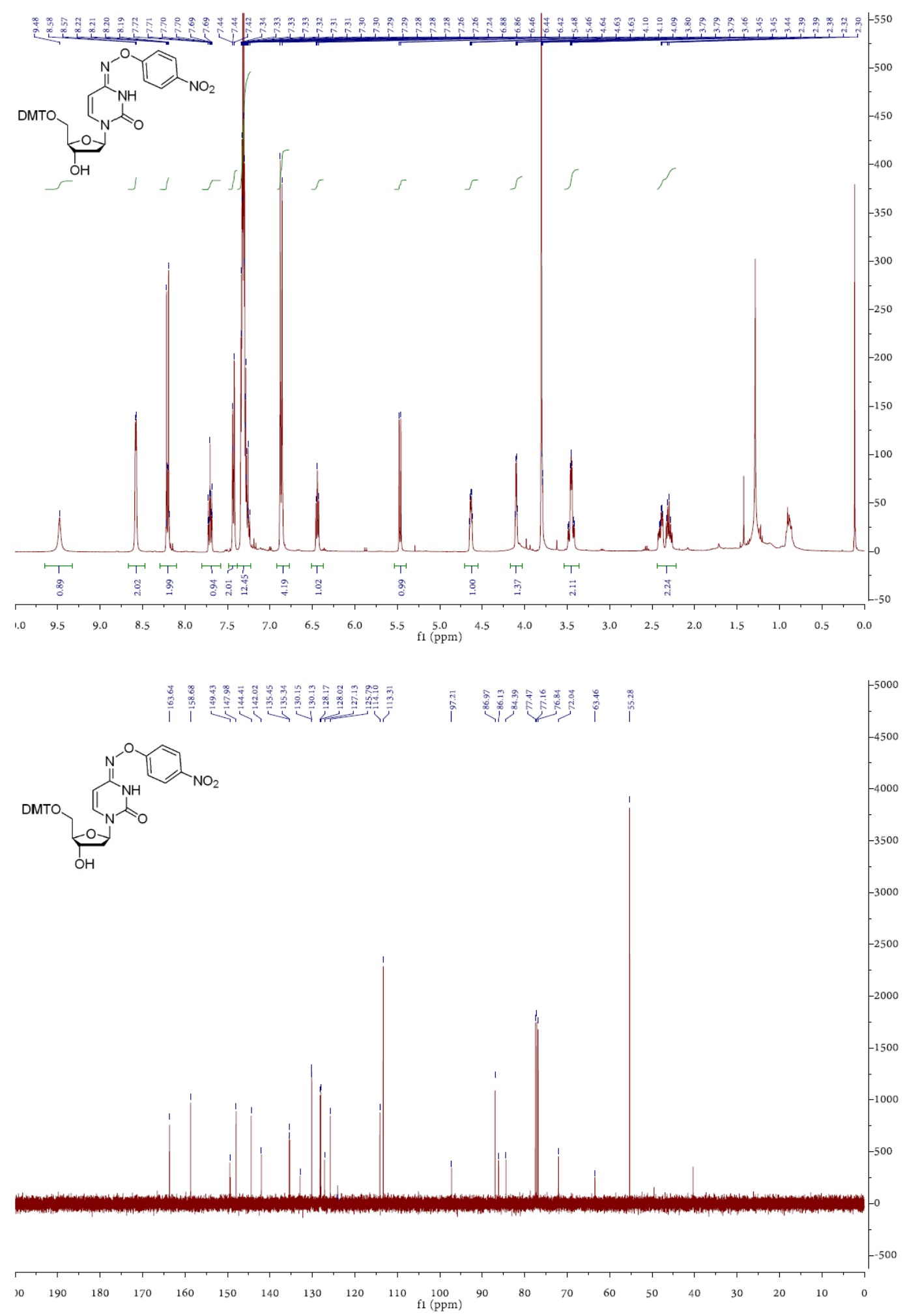

Figure S33. ${ }^{1} \mathrm{H}$ and ${ }^{13} \mathrm{C}$ NMR of 29a. 

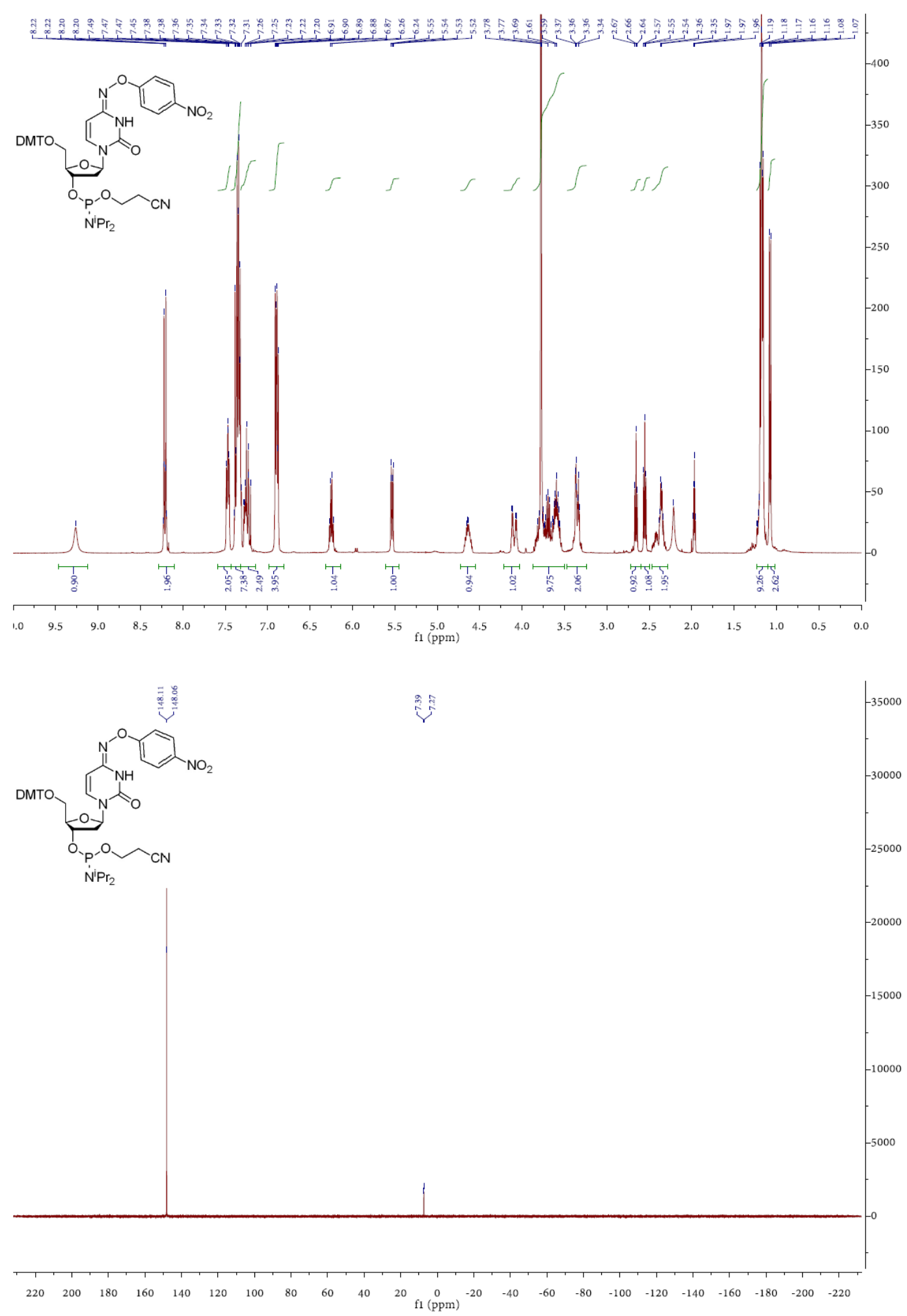


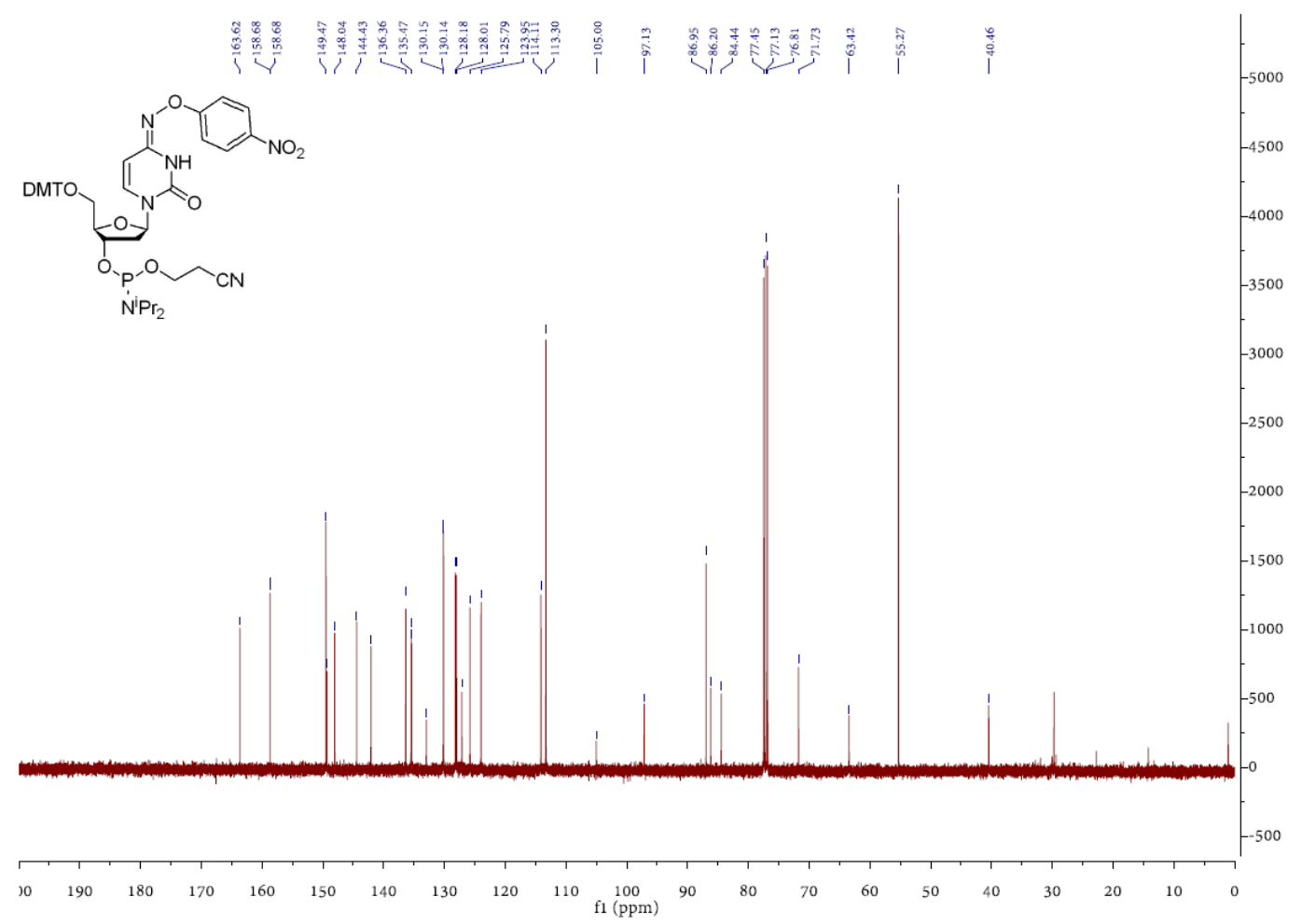

Figure S34. ${ }^{1} \mathrm{H},{ }^{31} \mathrm{P}$, and ${ }^{13} \mathrm{C}$ NMR of $\mathbf{3 0 a}$.

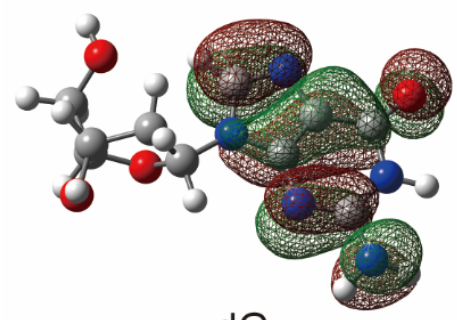

dG

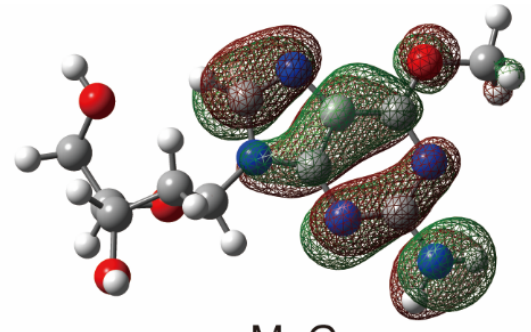

MeG

(HOMO: $-589.5 \mathrm{~kJ} / \mathrm{mol})$

Figure S35. Orbital contour plot of the HOMO for $\mathrm{dG}$ and $\mathrm{MeG}$ obtained by the density functional calculation at the PCM/B3LYP/6-31++G(d,p) level. Carbon, oxygen, nitrogen, and hydrogen atoms are denoted with gray, red, blue, and white balls, respectively. 


\section{References.}

(1) M. J. Frisch, G.W.T., H. B. Schlegel, G. E. Scuseria, M. A. Robb, , J. R. Cheeseman, G.S., V. Barone, B. Mennucci,, G. A. Petersson, H.N., M. Caricato, X. Li, H. P. Hratchian, , A. F. Izmaylov, J.B., G. Zheng, J. L. Sonnenberg, M. Hada, , M. Ehara, K.T., R. Fukuda, J. Hasegawa, M. Ishida, T. Nakajima, , Y. Honda, O.K., H. Nakai, T. Vreven, J. A. Montgomery, Jr., , J. E. Peralta, F.O., M. Bearpark, J. J. Heyd, E. Brothers, , K. N. Kudin, V.N.S., T. Keith, R. Kobayashi, J. Normand, , K. Raghavachari, A.R., J. C. Burant, S. S. Iyengar, J. Tomasi, , M. Cossi, N.R., J. M. Millam, M. Klene, J. E. Knox, J. B. Cross, et al. Gaussian 09 (Gaussian, Inc.), 2013, Revision E. 01.

(2) Münzel, M.; Szeibert, C.; Glas, A. F.; Globisch, D.; Carell, T. J. Am. Chem. Soc. 2011, 133, 5186.

(3) Davies, J.; Booth, S. G.; Essafi, S.; Dryfe, R. A. W.; Leonori, D. Angew. Chem. Int. Ed. 2015, $54,14017$.

(4) Barsotti, F.; Bartels-Rausch, T.; De Laurentiis, E.; Ammann, M.; Brigante, M.; Mailhot, G.; Maurino, V.; Minero, C.; Vione, D. Environ. Sci. \& Tech. 2017, 51, 7486. 